\title{
Endoscopic or surgical intervention for painful obstructive chronic pancreatitis (Review)
}

Ahmed Ali U, Pahlplatz JM, Nealon WH, van Goor H, Gooszen HG, Boermeester MA

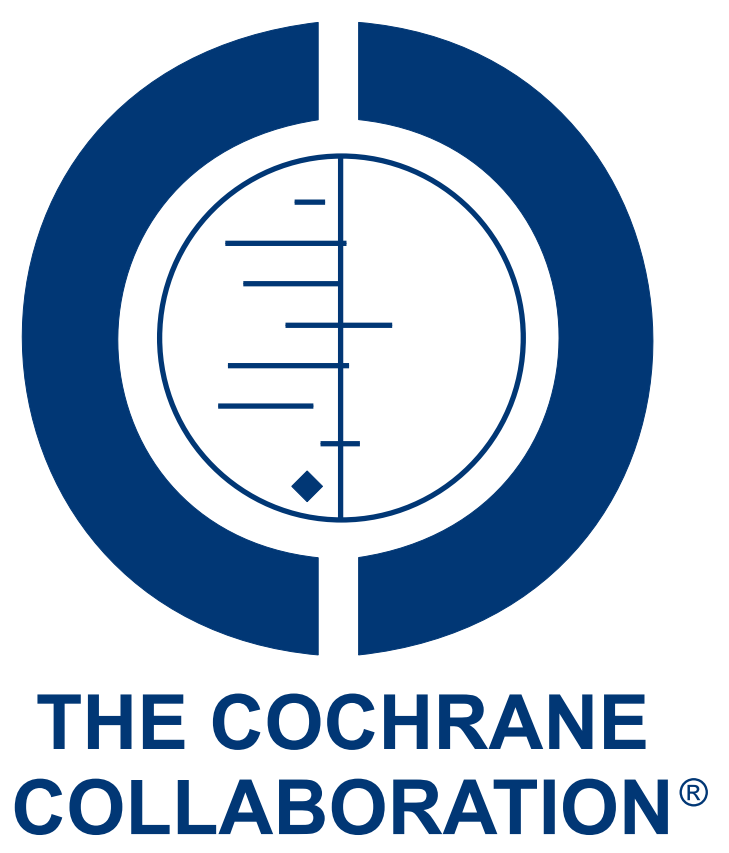

This is a reprint of a Cochrane review, prepared and maintained by The Cochrane Collaboration and published in The Cochrane Library 2012, Issue 1

http://www.thecochranelibrary.com

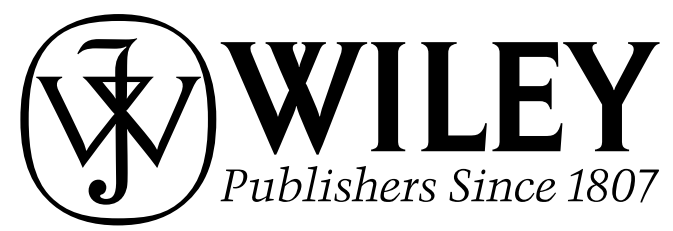

Endoscopic or surgical intervention for painful obstructive chronic pancreatitis (Review)

Copyright $\odot 2012$ The Cochrane Collaboration. Published by John Wiley \& Sons, Ltd. 
TABLE OF CONTENTS

HEADER . . . . . . . . . . . . . . . . . . . . . . . . . . . . . . . . . . 1

ABSTRACT . . . . . . . . . . . . . . . . . . . . . . . . . . . . . . . . . . . . . . . 1

PLAIN LANGUAGE SUMMARY . . . . . . . . . . . . . . . . . . . . . . . . . . . . . . . . . . . . . . . . . . . . .

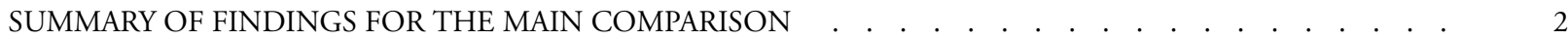

BACKGROUND . . . . . . . . . . . . . . . . . . . . . . . . . . . . . . . . . . . . . . . . . 6

OBJECTIVES . . . . . . . . . . . . . . . . . . . . . . . . . . . . . . . . . . . . . . . . . . . .

METHODS . . . . . . . . . . . . . . . . . . . . . . . . . . . . . . . . . . . . . . 6

RESUlTS . . . . . . . . . . . . . . . . . . . . . . . . . . . . . . . . . . . . . 9

Figure 1. . . . . . . . . . . . . . . . . . . . . . . . . . . . . . . . . . . . . 10

Figure 2. . . . . . . . . . . . . . . . . . . . . . . . . . . . . . . . . . . . . . 12

Figure 3. . . . . . . . . . . . . . . . . . . . . . . . . . . . . . . . . . . . . . 13

Figure 4. . . . . . . . . . . . . . . . . . . . . . . . . . . . . . . . . . . . . . 14

Figure 5. . . . . . . . . . . . . . . . . . . . . . . . . . . . . . . . . . . . . . 14

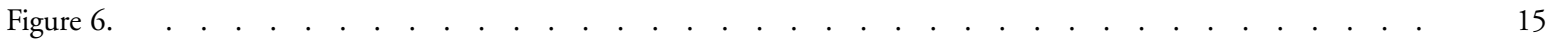

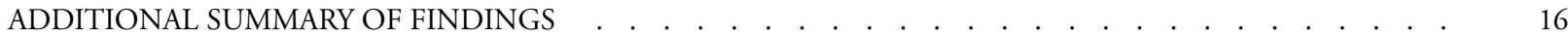

DISCUSSION . . . . . . . . . . . . . . . . . . . . . . . . . . . . . . . . . . . . . . 19

AUTHORS' CONCLUSIONS . . . . . . . . . . . . . . . . . . . . . . . . . . . . . . . . . . 21

ACKNOWLEDGEMENTS . . . . . . . . . . . . . . . . . . . . . . . . . . . . . . . . . 21

REFERENCES . . . . . . . . . . . . . . . . . . . . . . . . . . . . . . . . . . . . . . . . . . . . . 21

CHARACTERISTICS OF STUDIES . . . . . . . . . . . . . . . . . . . . . . . . . . . . . . . . . . . . . . .

DATA AND ANALYSES . . . . . . . . . . . . . . . . . . . . . . . . . . . . . . . . . . . . . 32

Analysis 1.1. Comparison 1 Endoscopy versus surgery, Outcome 1 Pain relief. . . . . . . . . . . . . . . . 32

Analysis 1.2. Comparison 1 Endoscopy versus surgery, Outcome 2 Complete and partial pain relief. . . . . . . . 33

Analysis 1.3. Comparison 1 Endoscopy versus surgery, Outcome 3 Endocrine pancreatic insufficiency (new onset). . 34

ADDITIONAL TABLES . . . . . . . . . . . . . . . . . . . . . . . . . . . . . . . . . . . . . . . . . . .

APPENDICES . . . . . . . . . . . . . . . . . . . . . . . . . . . . . . . . . . . . . . . .

HISTORY . . . . . . . . . . . . . . . . . . . . . . . . . . . . . . . . . . . . . . . 39

CONTRIBUTIONS OF AUTHORS . . . . . . . . . . . . . . . . . . . . . . . . . . . . . . . . . . . . . .

DECLARATIONS OF INTEREST . . . . . . . . . . . . . . . . . . . . . . . . . . . . . . . . . . . . . . . . . .

SOURCES OF SUPPORT . . . . . . . . . . . . . . . . . . . . . . . . . . . . . . . . . . . . . 40

DIFFERENCES BETWEEN PROTOCOL AND REVIEW . . . . . . . . . . . . . . . . . . . . . . 40

INDEX TERMS . . . . . . . . . . . . . . . . . . . . . . . . . . . . . . . . . . . . . 40

Endoscopic or surgical intervention for painful obstructive chronic pancreatitis (Review)

Copyright $\odot 2012$ The Cochrane Collaboration. Published by John Wiley \& Sons, Ltd. 


\title{
[Intervention Review] \\ Endoscopic or surgical intervention for painful obstructive chronic pancreatitis
}

\author{
Usama Ahmed Ali ${ }^{1}$, Johanna M Pahlplatz ${ }^{1}$, Wiliam H Nealon ${ }^{2}$, Harry van Goor ${ }^{3}$, Hein G Gooszen ${ }^{4}$, Marja A Boermeester ${ }^{5}$ \\ ${ }^{1}$ Department of Surgery, University Medical Center Utrecht, Utrecht, Netherlands. ${ }^{2}$ Department of Surgery, Vanderbilt University, \\ Nashville, TN, USA. ${ }^{3}$ Department of Surgery, Radboud University Nijmegen Medical Center, Nijmegen, Netherlands. ${ }^{4}$ Centre of \\ Evidence-based Surgery, Radboud University Nijmegen Medical Center, Nijmegen, Netherlands. ${ }^{5}$ Department of Surgery, Academic \\ Medical Center, University of Amsterdam, Amsterdam, Netherlands \\ Contact address: Usama Ahmed Ali, Department of Surgery, University Medical Center Utrecht, Heidelberglaan 100, P.O. Box 85500, \\ Utrecht, Utrecht, 3508 GA, Netherlands.U.ahmedali@gmail.com. u.ahmedali@umcutrecht.nl. \\ Editorial group: Cochrane Upper Gastrointestinal and Pancreatic Diseases Group. \\ Publication status and date: New, published in Issue 1, 2012. \\ Review content assessed as up-to-date: 3 November 2011.
}

Citation: Ahmed Ali U, Pahlplatz JM, Nealon WH, van Goor H, Gooszen HG, Boermeester MA. Endoscopic or surgical intervention for painful obstructive chronic pancreatitis. Cochrane Database of Systematic Reviews 2012, Issue 1. Art. No.: CD007884. DOI: 10.1002/14651858.CD007884.pub2.

Copyright (C) 2012 The Cochrane Collaboration. Published by John Wiley \& Sons, Ltd.

\begin{abstract}
A B S T R A C T
Background

Endoscopy and surgery are the treatment modalities of choice in patients with obstructive chronic pancreatitis. Physicians face the decision between endoscopy and surgery for this group of patients, without clear consensus.
\end{abstract}

Objectives

To assess and compare the effectiveness and complications of surgical and endoscopic interventions in the management of pain for obstructive chronic pancreatitis.

\section{Search methods}

We searched The Cochrane Library, MEDLINE, EMBASE and the Conference Proceedings Citation Index; and performed a crossreference search. Two review authors performed the selection of trials independently.

\section{Selection criteria}

All randomised controlled trials (RCTs) investigating endoscopic or surgical interventions for obstructive chronic pancreatitis. All trials were included irrespective of blinding, number of patients randomised and language of the article.

\section{Data collection and analysis}

Two authors independently extracted data from the articles. The methodological quality of included trials was evaluated. Authors were requested additional information in the case of missing data.

\section{Main results}

We screened 2082 publications and identified three eligible trials. Two trials compared endoscopic intervention to surgical intervention. These included a total of 111 patients, 55 in the endoscopic group and 56 in the surgical group. A higher proportion of patients with pain relief was found in the surgical group compared to the endoscopic group (partial or complete pain relief: RR 1.62, 95\% confidence

Endoscopic or surgical intervention for painful obstructive chronic pancreatitis (Review)

Copyright $\odot 2012$ The Cochrane Collaboration. Published by John Wiley \& Sons, Ltd. 
interval (CI) 1.11 to 2.37; complete pain relief: RR 2.45, 95\% CI 1.18 to 5.09). Surgical intervention resulted in improved quality of life and improved preservation of exocrine pancreatic function in one trial. The number of patients did not allow for a reliable evaluation of morbidity and mortality between the two treatment modalities. One trial compared surgical intervention to conservative treatment. It included 32 patients: 17 in the surgical group and 15 in the conservative group. The trial showed that surgical intervention resulted in a higher percentage of patients with pain relief and better preservation of pancreatic function. The trial had methodological limitations and the number of patients was relatively small.

\section{Authors' conclusions}

For patients with obstructive chronic pancreatitis and dilated pancreatic duct, this review showed that surgery is superior to endoscopy in terms of pain control. Morbidity and mortality seemed not to differ between the two intervention modalities, but the small trials identified do not provide sufficient power to detect the small differences expected in this outcome.

Regarding the comparison of surgical intervention versus conservative treatment, this review has shown that surgical intervention in an early stage of chronic pancreatitis seems to be a promising approach in terms of pain control and pancreatic function. Confirmation of these results is needed in other trials due to the methodological limitations and limited number of patients of the present evidence.

\section{PLAIN LANGUAGESUMMARY}

\section{Endoscopy or surgery for patients with chronic pancreatitis and dilated pancreatic duct}

Endoscopy and surgery are the treatments of choice in patients with chronic pancreatitis and a dilated pancreatic duct. In this review we compared these two intervention modalities. We found that surgery achieved pain relief in a higher proportion of patients than with endoscopy. Surgery also had other advantages like improved quality of life and reduced risk of developing exocrine pancreatic insufficiency. The studies seemingly showed no difference in complications after intervention between endoscopy and surgery, but lacked the power to establish this with sufficient reliability. We also compared surgery to conservative treatment. Results of one trial suggested that surgery early in the disease achieved better pain relief and preservation of pancreatic function. The trial, however, was small, which precluded drawing reliable conclusions.

Endoscopic or surgical intervention for painful obstructive chronic pancreatitis (Review) 


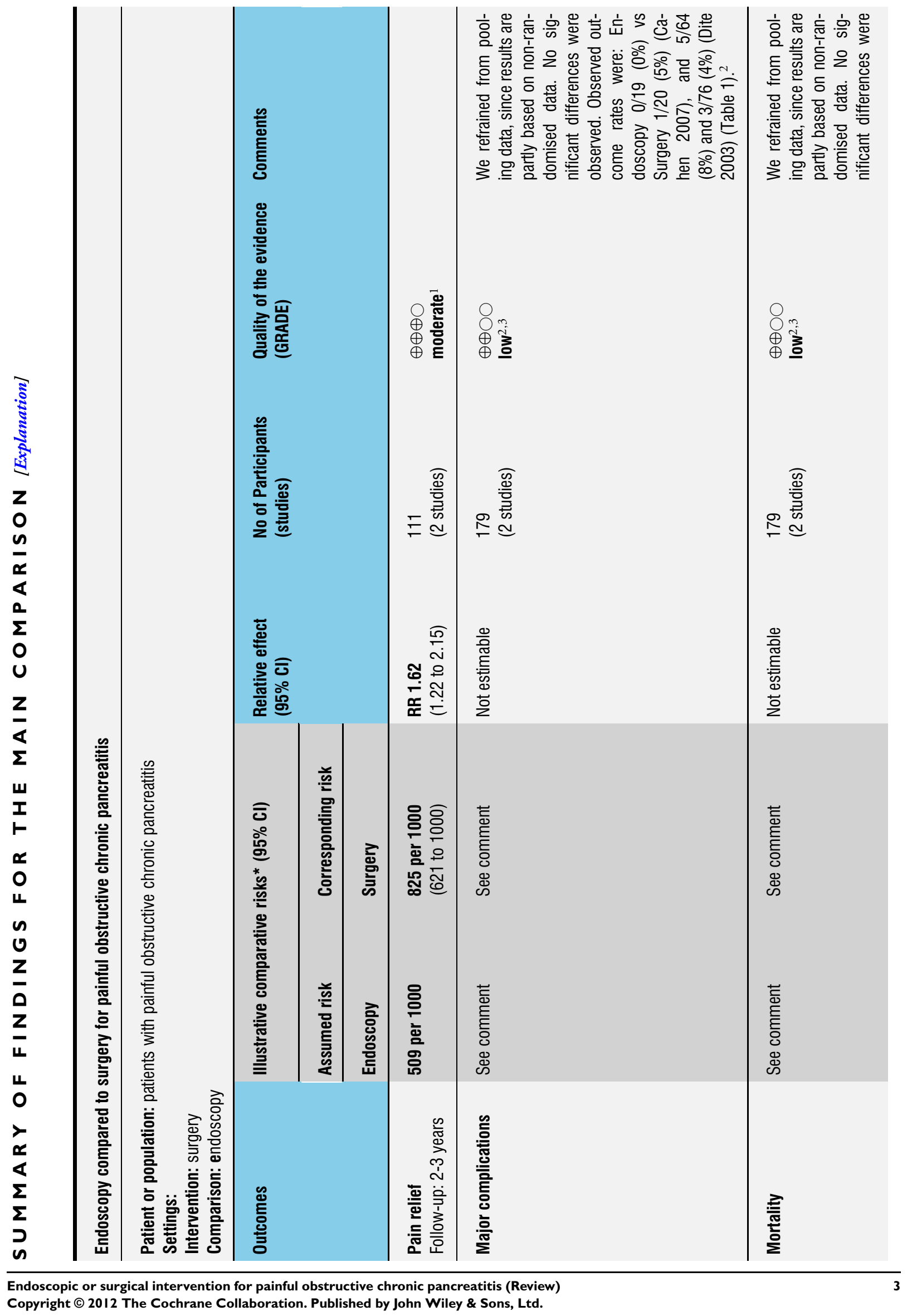




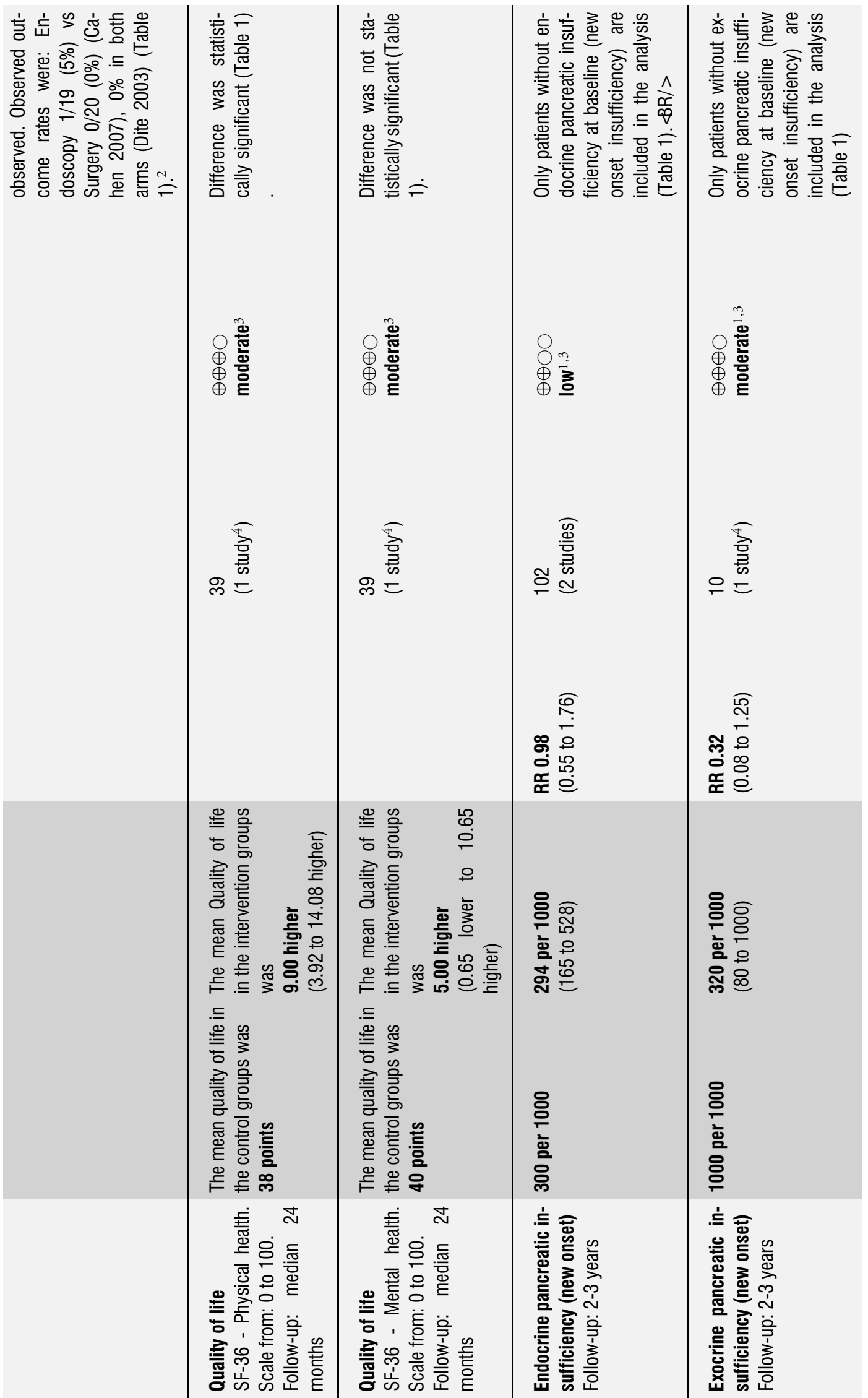

Endoscopic or surgical intervention for painful obstructive chronic pancreatitis (Review)

Copyright $\odot 2012$ The Cochrane Collaboration. Published by John Wiley \& Sons, Ltd. 


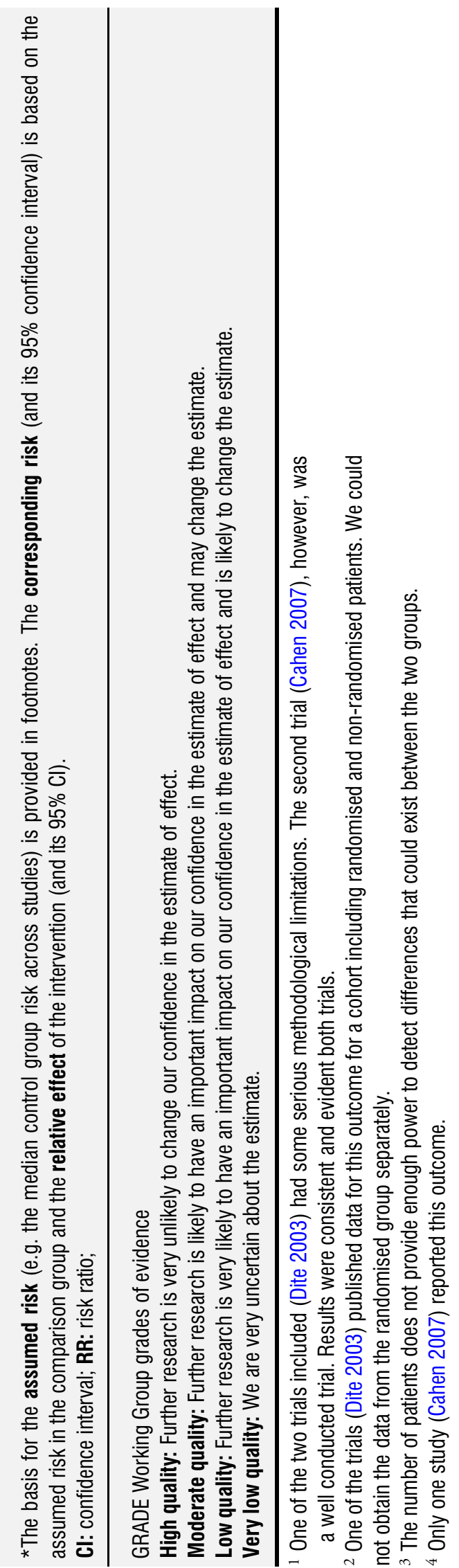

Endoscopic or surgical intervention for painful obstructive chronic pancreatitis (Review)

Copyright $\odot 2012$ The Cochrane Collaboration. Published by John Wiley \& Sons, Ltd. 


\section{B A C K G ROU N D}

\section{Description of the condition}

Chronic pancreatitis (CP) is a progressive inflammatory condition of the pancreas characterised by severe pain and damage to endocrine and exocrine pancreatic tissue. The incidence and prevalence of chronic pancreatitis in Western Europe are estimated to be around seven and 26 per 100,000, respectively (Dite 2001; Levy 2006; Spanier 2008). The etiology of CP is a complex multifactorial process (Witt 2007). In the Western world alcohol is the leading contributing factor. Genetics, auto-immunity, metabolic abnormalities (hypertriglyceridaemia, hypercalcaemia) and anatomical malformations (pancreas divisum) play a role as well in the development of CP (Witt 2007).

Pain is the characteristic clinical symptom of CP. Management of this disease is, therefore, mostly focused towards pain alleviation (AGA 1998; van Esch 2006). Longstanding CP is also associated with development of endocrine and exocrine insufficiency, which may result in diabetes, malabsorption, weight loss and deterioration of the patient's general condition (Pezzilli 2005; Wehler 2004). Additionally, CP can be complicated by pancreatic pseudocyst formation, abscess formation, stenosis of the common bile duct and an increased risk of pancreatic cancer (Lankisch 2001).

\section{Description of the intervention}

In patients with obstructive $\mathrm{CP}$ it is believed that ductal and parenchymal hypertension, caused by an elevated pressure in the main pancreatic duct, is the source of pain (Fasanella 2007). Fibrosis within the chronically inflamed pancreas is assumed to contribute to elevated pressure by limiting the ability of the gland to expand during periods of exocrine secretion (Fasanella 2007; Gourgiotis 2007). Strictures and elevated pressure are contributing factors to the formation of stones in the pancreatic duct, which may further limit the ability of the gland to excrete its exocrine products normally. Endoscopy and surgery are considered the treatment modalities of choice in the case of painful obstructive pancreatitis. The aim of both modalities is to alleviate the pressure of the pancreatic duct and ensure adequate drainage of pancreatic excretions.

\section{How the intervention might work}

Endoscopic therapy attempts to relieve the pressure in the pancreatic duct by ensuring good drainage of pancreatic juices into the intestines. This is typically done by means of endoscopic retrograde cholangiopancreatography (ERCP). Endoscopic treatment may involve papillotomy of the papilla of Vater, dilation of strictures, removal of stones (with or without lithotrypsy) and placement of stents in the pancreatic duct (Rösch 2002). Endoscopic intervention is less invasive than surgery and patients can usually be discharged in about one to two days. Usually, however, more than one endoscopic intervention is needed to achieve satisfactory results, and in some patients subsequent surgery is still needed. Overall, endoscopic treatment achieves complete or partial pain relief in approximately $74 \%$ of patients (van der Gaag 2007).

Surgical interventions for CP can be classified into resection and drainage procedures (Gourgiotis 2007; van der Gaag 2007). In a drainage procedure the pancreatic duct is opened over its full length and subsequently a side-to-side anastomosis with the jejunum is performed (that is pancreaticojejunostomy). In resection procedures, the affected head or tail of the pancreas is resected. After duodenum preserving pancreatic head (Beger) resection or pancreaticoduodenectomy the open end of the remnant pancreatic duct is connected to the small bowel. For distal pancreatic (pancreatic tail) resections a bowel connection for drainage is not routinely needed. There are also mixed drainage and resection procedures, in which a local pancreatic resection (mostly of the pancreatic head) is combined with a partial drainage procedure (for example Frey or Bern operations) (Strate 2005). Patients typically remain hospitalized for one to two weeks after surgery (Cahen 2007). Surgical interventions accomplish partial or complete pain relief in approximately $80 \%$ of patients (van der Gaag 2007).

\section{Why it is important to do this review}

There is no clear consensus regarding the decision between endoscopy and surgery for patients with painful obstructive CP. Several reviews describe results of endoscopic and surgical procedures separately, but inference from these reports is difficult due to the lack of head-to-head comparisons (Gourgiotis 2007; Tringali 2008; van der Gaag 2007). One review of randomised clinical trials on endoscopic versus surgical interventions was published recently, but the methodology was not explicit and the review lacked a clear conclusion (Deviere 2008). We, therefore, aimed to review and summarise the evidence for both treatment modalities.

\section{O B J E C T I VES}

To assess and compare the effectiveness and complications of surgical and endoscopic interventions in the management of pain for obstructive chronic pancreatitis.

\section{METHOD S}

\section{Criteria for considering studies for this review}




\section{Types of studies}

All randomised controlled trials (RCTs) investigating endoscopic or surgical interventions for obstructive chronic pancreatitis (that is with a dilated panceatic duct). All trials were included irrespective of blinding, number of patients randomised and language of the article.

\section{Types of participants}

Trials including adults with confirmed chronic pancreatitis (CP), pancreatic duct dilation and pain were eligible for this review. Pain was the primary indication for the interventions.

\section{Types of interventions}

Studies with any of the following comparisons were included.

- Endoscopic versus surgical intervention.

- Endoscopic intervention versus conservative treatment.

- Surgical intervention versus conservative treatment.

We used the following definitions for the different treatment modalities.

- Endoscopic intervention: an endoscopic retrograde cholangiopancreatography (ERCP) performed with therapeutic intent and in which one of papillotomy, dilation of the pancreatic duct or placement of a pancreatic ductal stent was performed.

- Surgical intervention: any surgical procedure used for the treatment of obstructive CP, including pancreaticojejunostomy $(\mathrm{PJ})$, resection-drainage procedures (e.g. Frey, Beger) or a (pylorus preserving) pancreaticoduodenectomy.

- Conservative treatment: non-invasive therapy, mainly medical treatment for pain and nutritional supportive treatment.

\section{Types of outcome measures}

\section{Primary outcomes}

- Pain relief: proportion of patients achieving pain relief compared to the situation prior to intervention. Since pain is a subjective outcome and many different scores are used, we did not use a strict definition of pain relief. We classified the observed pain relief as either complete or partial. Partial pain relief was defined as a decrease in pain of at least $50 \%$ compared to baseline, without achieving complete pain relief. We conducted analysis for complete and partial pain relief separately, and for total proportion of patients experiencing pain relief (both partial and complete).

- Major post-interventional complications, including intraabdominal abscess, ileus necessitating surgery, pancreatitis flareup, bleeding, anastomotic leakage, sepsis, abdominal fascial dehiscence (Platzbauch) and myocardial infarction.

- Mortality.

\section{Secondary outcomes}

- Quality of life.

- Minor post-interventional complications: these included wound infections, pneumonia, cholecystitis, prolonged ileus (not necessitating intervention), fistulas, urinary tract infections, urinary retention and deep venous thrombosis.

- New onset endocrine and exocrine pancreatic insufficiency.

- Number of endoscopic and surgical procedures related to the treatment of $\mathrm{CP}$.

- Change in nutritional status (body weight or body mass index (BMI)) after intervention.

- Duration of hospital stay.

\section{Search methods for identification of studies}

\section{Electronic searches}

We searched the following databases.

- The Cochrane Library, 2011, Issue 4 (search strategy in Appendix 1):

- Cochrane Database of Systematic Reviews;

- Database of Abstracts of Reviews of Effects (DARE);

- Cochrane Central Register of Controlled Trials

(CENTRAL).

- MEDLINE via Ovid (from 1950 to November 2011)

(Appendix 2).

- EMBASE via Ovid (from 1980 to November 2011)

(Appendix 3).

- Conference Proceedings Citation Index - Science (CPCI-S) (from 1990 to February 2010) (Appendix 4).

We developed the search strategies in cooperation with the Cochrane Upper Gastrointestinal and Pancreatic Diseases Group (see Acknowledgements).

\section{Searching other resources}

We performed a cross-reference search of all included randomised trials and relevant reviews identified during the search process. We also requested additional information by letter or e-mail from all authors of included trials on any published, unpublished or ongoing trials.

\section{Data collection and analysis}

We conducted this review according to the recommendations of the Cochrane Handbook for Systematic Review of Interventions ( Higgins 2008). 


\section{Selection of studies}

Two review authors (UAA and JMP) performed the selection of trials independently. First, they screened titles and abstracts and selected all potentially relevant publications, including those where the relevance was uncertain. Subsequently, they reviewed the fulltext of all selected publications and selected trials meeting the selection criteria. In the case of disagreements consensus was reached by discussion.

\section{Data extraction and management}

Two review authors (UAA and JMP) independently extracted all relevant data. For each study the review authors extracted patient characteristics, study characteristics, data needed for the methodological quality assessment of the study and the primary and secondary outcomes, according to availability. Data regarding patient characteristics included number of patients in each group, age, gender, BMI and type of pain (A or B) according to the Ammann classification (Ammann 1999). Data regarding study characteristics included study design, sample size information, inclusion and exclusion criteria of the study, follow-up period, loss to followup, surgical and endoscopic experience and information regarding surgical and endoscopic techniques. These data are presented in the Characteristics of included studies table.

\section{Assessment of risk of bias in included studies}

Based on the recommendations of the Cochrane Handbook for Systematic Reviews of Interventions and available literature, we assessed the methodological quality of RCTs by using the tool for assessing risk of bias (Higgins 2008; Kjaergard 2001; Moher 1998; Schulz 1995). We used the following definitions of the items in this tool.

\section{Sequence allocation}

- Adequate, if the allocation sequence was generated by a computer or random number table. Drawing of lots, tossing of a coin, shuffling of cards, or throwing dice was considered adequate if a person who was not otherwise involved in the recruitment of participants performed the procedure.

- Unclear, if the trial was described as randomised but the method used for generation of the allocation sequence was not described.

- Inadequate, if a system involving dates, names or alternating allocation was used for the allocation of patients.

\section{Allocation concealment}

- Adequate, if the allocation of patients involved a central independent unit, on-site locked computer, or sealed envelopes.

- Unclear, if the trial was described as randomised but the method used to conceal the allocation was not described.

- Inadequate, if the allocation sequence was known to the investigators who assigned the participants.

\section{Blinding}

- Adequate, if the trial was described as blind to participants or assessors and the method of blinding was described. We are well aware that it is very difficult to properly blind trials comparing endoscopic or surgical treatments.

- Unclear, if the trial was described as (double) blind, but the method of blinding was not described.

- Inadequate, if the trial was not blinded.

\section{Incomplete data outcome}

- Adequate, if the percentage of dropouts did not exceed $20 \%$, and numbers and reasons for dropouts and withdrawals in all intervention groups were described.

- Unclear, if the report gave the impression that there had been no dropouts or withdrawals but this was not specifically stated.

- Inadequate, if the percentage of dropouts exceeded $20 \%$, or the numbers and reasons for dropouts and withdrawals were not described.

\section{Selective outcome reporting}

- Adequate, when it was clear that the published reports included all expected outcomes, including those that were prespecified.

- Unclear, if insufficient information was provided to permit clear judgement of this aspect.

- Inadequate, if all relevant outcomes and all the study's prespecified outcomes were not reported, or if they were incompletely reported.

\section{Other sources of bias}

- Adequate, if the study appeared to be free of other sources of bias.

- Unclear, if a risk of potentially important bias existed but sufficient information to assess this bias was lacking.

- Inadequate, if one or more sources of potentially important biases could be identified in the study (e.g. extreme baseline imbalances or other imbalances in study design).

\section{Measures of treatment effect}

We conducted statistical analysis of binary data using risk ratio (RR) as the summary statistic. For continuous outcomes we used mean differences (MD) as the summary statistic.

\section{Assessment of heterogeneity}

We calculated the heterogeneity using the $\mathrm{Chi}^{2}$ test and quantified the inconsistency in study effects by the $\mathrm{I}^{2}$ statistic (Higgins 2002). We considered a $\mathrm{Chi}^{2}$ test with a $\mathrm{P}$ value of $<0.10$ to indicate the 
presence of heterogeneity, and an $\mathrm{I}^{2}$ statistic $>50 \%$ to suggest a marked inconsistency in effect between studies.

\section{Assessment of reporting biases}

Due to the low number of identified studies, funnel plots were not useful in assessing the presence of publication bias. We, therefore, refrained from using them.

\section{Data synthesis}

Depending on the availability of appropriate evidence, we conducted the following comparisons in this review.

- Endoscopic intervention versus surgical intervention.

- Endoscopic intervention versus conservative treatment.

- Surgical intervention versus conservative treatment.

If appropriate data were available, meta-analysis was conducted. Otherwise, we conducted a narrative review of the identified evidence. For the meta-analysis, we used the fixed-effect model if no heterogeneity was present $\left(\mathrm{Chi}^{2}\right.$ test $\mathrm{P}>0.1$ and $\left.\mathrm{I}^{2}<50 \%\right)$. In all other cases we used the random-effects model.

Due to insufficient numbers of trials, we were not able to perform a subgroup analysis according to the methodological quality of the included trials. The methodological quality of trials has been presented using the criteria of the risk of bias assessment tool described earlier, and has been taking into consideration when discussing the results of the review.

We conducted statistical analysis using the statistical package Review Manager (RevMan) provided by The Cochrane Collaboration.

\section{R E S U L T S}

\section{Description of studies}

See: Characteristics of included studies; Characteristics of excluded studies; Characteristics of ongoing studies.

\section{Results of the search}

We performed the search on 3 November 2011 and obtained a total of 2082 publications. We screened titles and abstract of all publications and excluded 2060 publications. Twenty-two potentially relevant publications remained for full-text reviewing. One publication was a study protocol of an ongoing trial (see Characteristics of ongoing studies). Two publications described a randomised trial of endoscopy versus extracorporeal shock-wave lithotripsy (ESWL). Since ESWL can not be considered as conservative treatment, this trial did not fulfil our inclusion criteria and was excluded (see Characteristics of excluded studies). Eleven publications were excluded for other reason (see Characteristics of excluded studies). Finally, we included five publications describing three distinct trials; one trial was described in three publications (Cahen 2007) (see Characteristics of included studies).

A cross-reference search of included trials and three additional reviews (Deviere 2008; Gourgiotis 2007; van der Gaag 2007) yielded no new eligible publications. Figure 1 is a flow-chart depicting the flow of the selection process. 
Figure I. Study flow diagram.

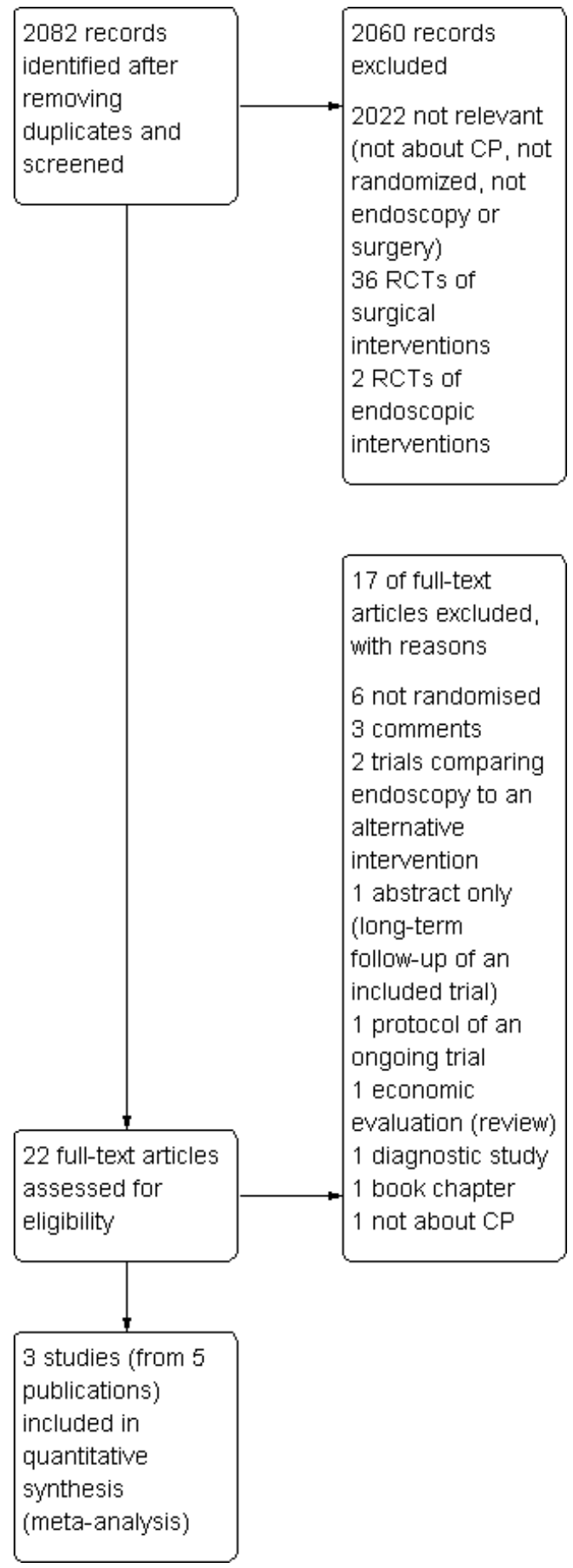

Endoscopic or surgical intervention for painful obstructive chronic pancreatitis (Review) 


\section{Included studies}

Two trials compared endoscopic intervention to surgical intervention (Cahen 2007; Dite 2003). One compared surgical intervention to conservative treatment (Nealon 1993). We did not identify any trials comparing endoscopic intervention to conservative treatment. We did encounter one ongoing trial comparing endoscopic intervention to sham endoscopy (Characteristics of ongoing studies). The characteristics of the included trials are described in the table 'Characteristics of included studies'. A brief summary of the most important characteristics is found below.

\section{Studies comparing endoscopic versus surgical intervention}

The two trials (Cahen 2007; Dite 2003) included a total of 111 patients, of whom 55 were in the endoscopic group and 56 in the surgical group.

Cahen 2007 randomised 39 patients with advanced CP (all patients needed opioid analgesics before study inclusion), a dilated pancreatic duct $(>5 \mathrm{~mm}$ ) and without pancreatic head enlargement between endoscopy (19 patients) and surgery (20 patients). The endoscopic intervention consisted of drainage of the pancreatic duct by ERCP with dilatation of strictures and stent placement in the pancreatic duct, as necessary. In the case of persistent strictures of the pancreatic duct, repeated dilation and stenting were performed until patency of the duct was achieved. Patients with large stones in the pancreatic duct $(>7 \mathrm{~mm})$ underwent extracorporeal shock-wave lithotripsy (ESWL) before drainage. The surgical group underwent surgical drainage of the pancreatic duct by a longitudinal pancreaticojejunostomy as the intended treatment. In one patient, a Whipple procedure was performed because of peripancreatic inflammation. In another patient, stone extraction required a Frey procedure. The primary outcome was pain as assessed by the Izbicki pain score (Izbicki 1998). Secondary outcomes were proportion of patients with pain relief, quality of life (SF-36), complications, mortality, duration of hospital stay, number of hospital readmittances, number of performed procedures, change in pancreatic function, rate of conversion from endoscopic treatment to surgery and technical success of the intervention. Follow-up was two years. The study was prematurely terminated by the safety committee on the bases of the significant difference in outcome favouring the surgical group, with a P value of less than 0.001 regarding the primary outcome (pain on the Izbicki pain score).

Dite 2003 included 140 patients in the study but only randomised 72 patients. The other 68 patients refused to be randomised in the trial due to an outspoken preference for one of the treatment modalities. Dite 2003 reported some outcomes for the randomised group separately. However, baseline characteristics and other out- comes (for example complications) were only reported for the complete cohort.

In the randomised group 36 patients were allocated to each of the two groups. All patients had advanced CP (at least three years of failed medical management) and obstruction of the pancreatic duct. Patients with enlargement of the pancreatic head were also included. Endoscopic treatment consisted of drainage of the pancreatic duct by ERCP with dilatation of strictures and stent placement in the pancreatic duct, as necessary. In the case of persistent strictures of the pancreatic duct, repeated dilation and stenting were performed until patency of the duct was achieved. ESWL was not performed as part of the endoscopic treatment. The surgical group underwent any type of drainage or resection procedure considered appropriate by the surgeon. Data on the specific operation were only reported for the complete cohort $(80 \%$ resection procedures and $20 \%$ drainage procedures). Primary outcomes were pain relief and necessity for further intervention. Secondary outcomes were change in body weight, presence of diabetes, complications and mortality. Follow-up was five years.

\section{Studies comparing surgical intervention versus conservative treatment}

Nealon 1993 was primarily a report of a cohort of 143 patients with CP followed prospectively for 47.3 months. Within this cohort a small pilot trial was conducted comparing surgical treatment to conservative treatment. In this review we only included data from the randomised trial.

In the published version of the trial, 17 patients with mild to moderate CP (graded using a self developed grading system, see Characteristics of included studies) and a dilated pancreatic duct were randomised. Nine and eight patients were allocated to the surgical and the conservative group, respectively. The only outcome reported was the change in CP grade during follow-up. We contacted the author for additional data and he provided us with an update of the trial including data concerning an additional 15 patients that had been included since the publication.

The trial, therefore, included 32 patients with mild to moderate (early stage) CP and dilated pancreatic duct, allocated to either early surgical treatment (17 patients) or conservative treatment (15 patients). The surgical group was treated with surgical drainage of the pancreatic duct by a longitudinal pancreaticojejunostomy. The conservative group was kept on non-invasive treatment (specific treatment modalities unspecified). Pain and endocrine and exocrine pancreatic function were reported as outcomes. The median follow-up period was 124 months.

\section{Excluded studies}

Endoscopic or surgical intervention for painful obstructive chronic pancreatitis (Review) 
All excluded publications that were not obviously excluded based on title and abstract alone (that is full-text reviewing was necessary for exclusion) are listed with the reason for exclusion in the table 'Characteristics of excluded studies'. Reasons for exclusion of these studies were: non-randomised trial (five publications), comment (two publications), study not about CP (one publication) and a book chapter (one publication).

\section{Risk of bias in included studies}

Risk of bias varied considerably between the three included trials. An overview of the different aspects of the risk of bias are illustrated in the risk of bias summary figures (Figure 2; Figure 3). A detailed description of the risk of bias assessment can be found in the 'Characteristics of included studies' table.

Figure 2. Risk of bias graph: review authors' judgements about each risk of bias item presented as percentages across all included studies.

\begin{tabular}{|c|c|c|c|c|c|c|}
\hline \multicolumn{7}{|c|}{ Random sequence generation (selection bias) } \\
\hline \multicolumn{7}{|c|}{ Allocation concealment (selection bias) } \\
\hline \multicolumn{7}{|c|}{ Blinding (performance bias and detection bias) } \\
\hline \multicolumn{7}{|c|}{ Incomplete outcome data (attrition bias) } \\
\hline \multicolumn{7}{|c|}{ Selective reporting (reporting bias) } \\
\hline \multicolumn{7}{|c|}{ Other bias } \\
\hline & & $0 \%$ & $25 \%$ & $50 \%$ & $75 \%$ & $100 \%$ \\
\hline Low risk of bias & Unclear risk & of bias & & gh ris & & \\
\hline
\end{tabular}


Figure 3. Methodological quality summary: review authors' judgements about each methodological quality item for the three included trials.

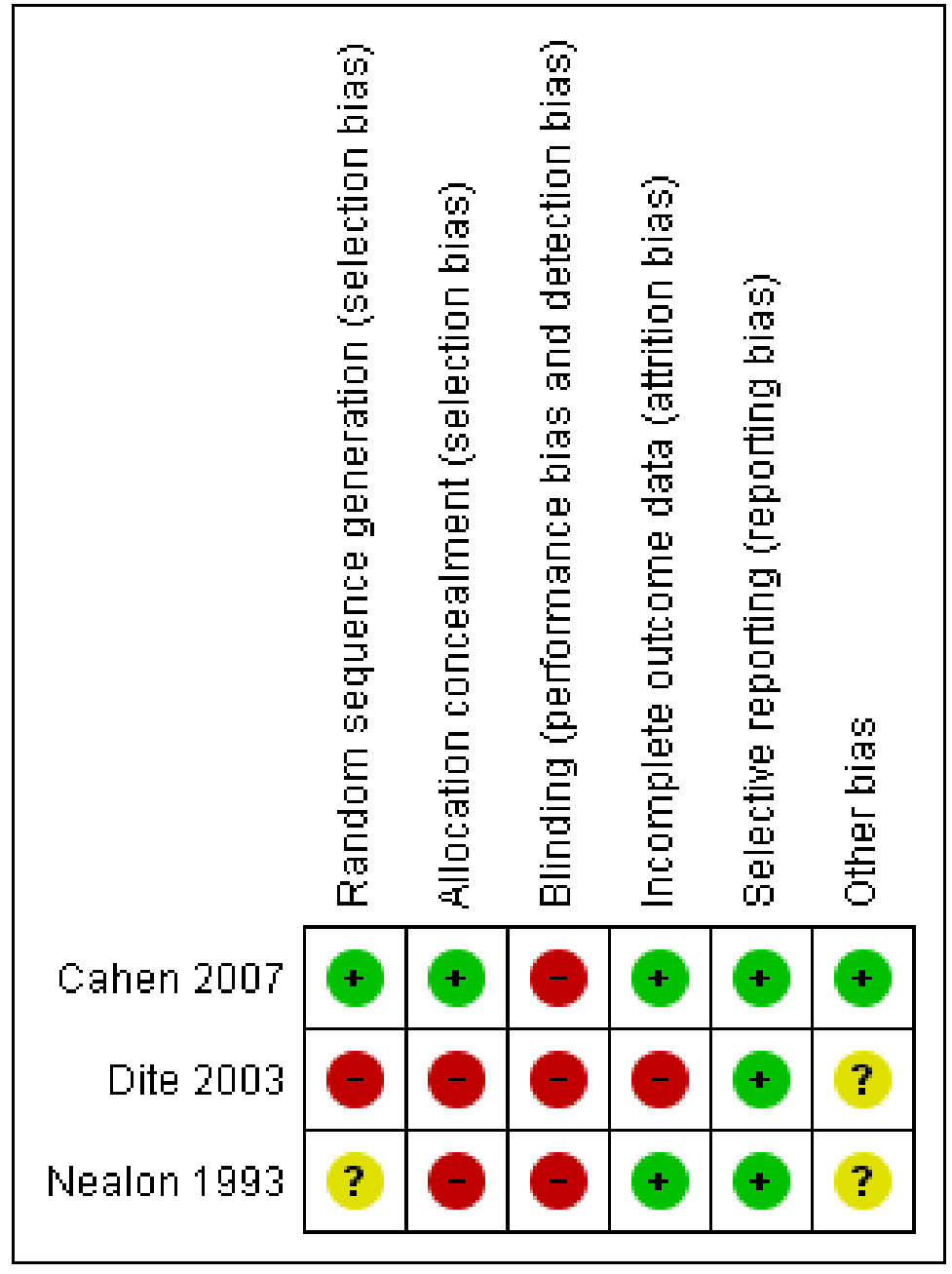

Cahen 2007 was a well performed study with low risk of bias. Dite 2001 had many methodological short-comings, including pseudorandomisation (allocation by alternation), unconcealed allocation, lack of baseline characteristics and lack of an intention-to-treat analysis (only a per protocol analysis was performed). For Nealon 1993 the methodological quality was not well reported. Therefore, important aspects remained unclear.

\section{Effects of interventions}

See: Summary of findings for the main comparison Endoscopy compared to surgery for painful obstructive chronic pancreatitis; Summary of findings 2 Surgery compared to conservative treatment for painful obstructive chronic pancreatitis

\section{Endoscopic versus surgical intervention}

Two studies comparing endoscopic versus surgical treatment were identified (Cahen 2007; Dite 2003). The two studies mostly reported different outcomes. Pooling of data was only possible in regard to two outcomes: pain relief and new onset endocrine pancreatic insufficiency. A narrative review is provided for other outcomes. Results of all outcomes considered to be of critical importance according to the GRADE guideline (scored 7 or higher on a 9-point score) were summarised in the Summary of findings for the main comparison. These outcomes were pain relief, major complications and mortality, quality of life, and endocrine and exocrine pancreatic insufficiency.

Pain relief 
Both studies reported a higher proportion of patients with pain relief (partial or complete) in the surgical group compared to the endoscopic group (RR 1.62, 95\% confidence interval (CI) 1.22 to 2.15) (Analysis 1.1; Figure 4). The proportion of patients with complete pain relief was higher in the surgical group (RR 2.45, $95 \%$ CI 1.18 to 5.09 ) but there was no difference in the proportion of patients with partial pain relief (Analysis 1.2; Figure 5).

Figure 4. Forest plot of comparison: I Endoscopy versus surgery, outcome: I.I Pain relief.

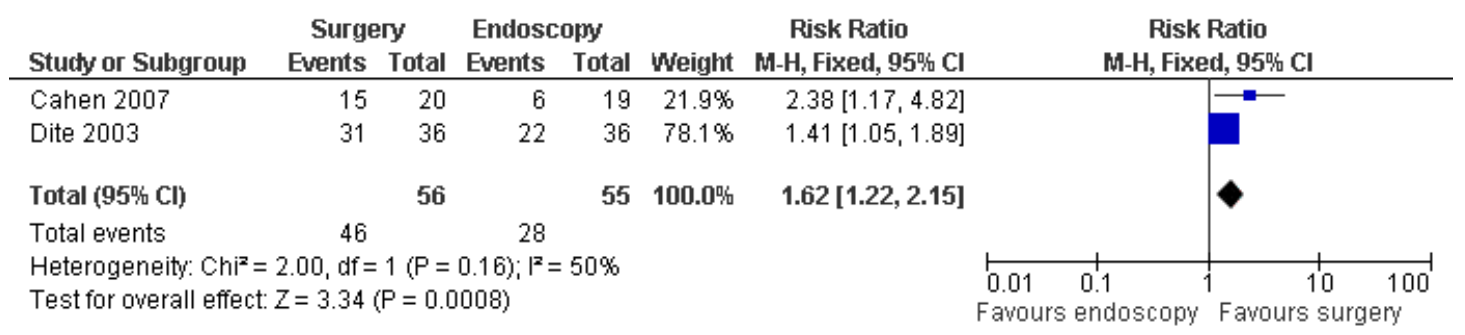

Figure 5. Forest plot of comparison: I Endoscopy versus surgery, outcome: I.2 Complete and partial pain relief.

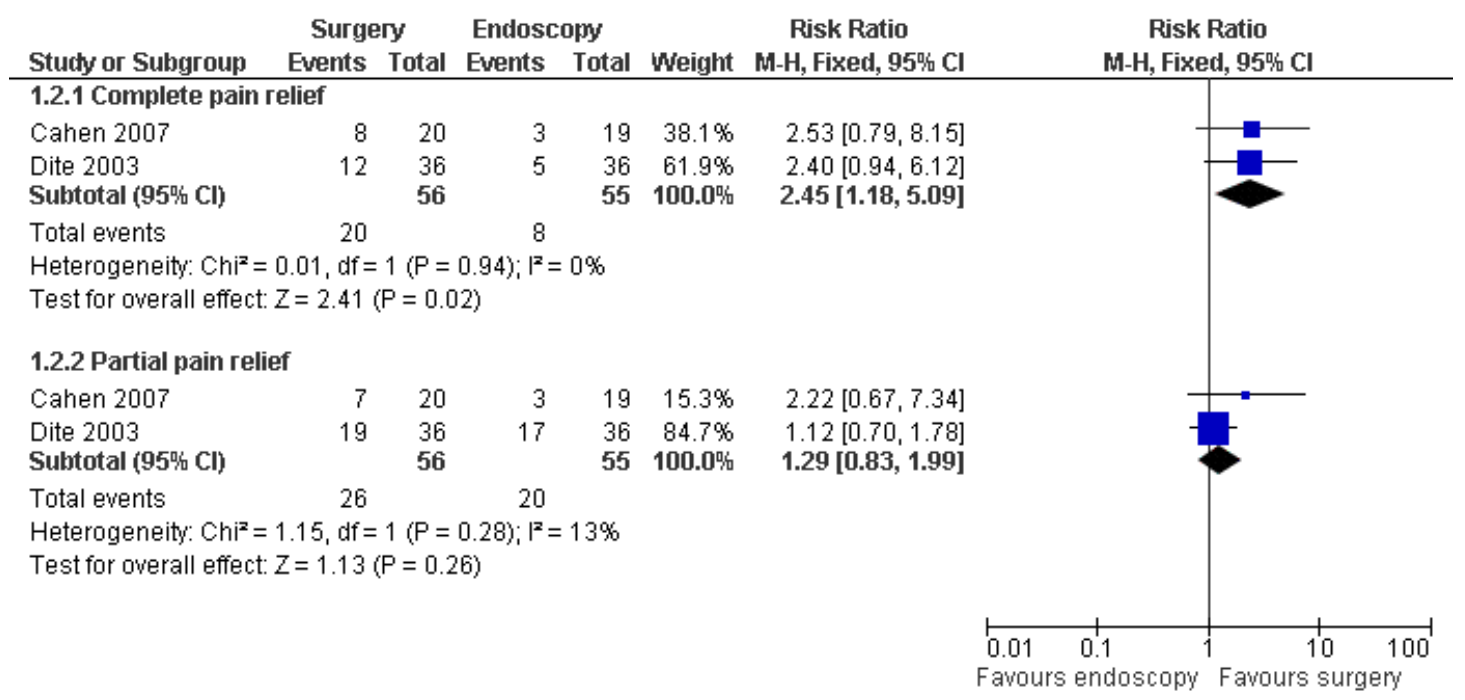

\section{Major post-interventional complications}

Both studies reported on major complications associated with study interventions (Table 1). There was no evidence for a differ-

\section{Mortality}

Endoscopic or surgical intervention for painful obstructive chronic pancreatitis (Review) 
Both studies reported on mortality. One death was reported in the endoscopic group (Table 1). There was, therefore, no evidence for a difference between the two groups.

\section{Quality of life}

Cahen 2007 reported the quality of life in both groups using the SF-36 quality of life instrument (Brazier 1992) (Table 1). The study showed that patients undergoing surgery scored higher (better) on the physical health component of the SF-36 quality of life scale. No difference was observed in the mental health component of the same instrument.

\section{Minor post-interventional complications}

Both studies reported on minor complications associated with the study interventions (Table 1). There was no evidence for a difference between the surgical and endoscopic interventions in terms of these complications.

\section{Pancreatic function}

Endocrine pancreatic function was reported by both studies. The proportion of new onset endocrine pancreatic insufficiency was pooled (Analysis 1.3; Figure 6). There was no evidence for a difference between the two groups.

\section{Figure 6. Forest plot of comparison: I Endoscopy versus surgery, outcome: I.3 Endocrine pancreatic}

insufficiency (new onset).

\begin{tabular}{|c|c|c|c|c|c|c|c|}
\hline \multirow[b]{2}{*}{ Study or Subgroup } & \multicolumn{2}{|c|}{ Surgery } & \multicolumn{2}{|c|}{ Endoscopy } & \multicolumn{2}{|r|}{ Risk Ratio } & \multirow{2}{*}{$\begin{array}{c}\text { Risk Ratio } \\
\text { M-H, Fixed, 95\% Cl }\end{array}$} \\
\hline & Events & Total & Events & Total & Weight & M-H, Fixed, 95\% $\mathrm{Cl}$ & \\
\hline Cahen 2007 & 1 & 16 & 3 & 14 & $21.1 \%$ & $0.29[0.03,2.50]$ & \begin{tabular}{c|c}
- & \\
\end{tabular} \\
\hline Dite 2003 & 14 & 36 & 12 & 36 & $78.9 \%$ & $1.17[0.63,2.16]$ & \\
\hline Total $(95 \%$ Cl) & & 52 & & 50 & $100.0 \%$ & $0.98[0.55,1.76]$ & \\
\hline Total events & 15 & & 15 & & & & \\
\hline $\begin{array}{l}\text { Heterogeneity: Chi } \\
\text { Test for overall effec }\end{array}$ & $\begin{array}{l}1.53, d f= \\
Z=0.06\end{array}$ & $\begin{array}{l}1(P= \\
P=0.9\end{array}$ & $\begin{array}{l}0.22) ; 1^{2}= \\
15)\end{array}$ & $35 \%$ & & & \begin{tabular}{ccccc|}
0.01 & 0.1 & 1 & 10 & 100 \\
Favours endoscopy & Favours surgery
\end{tabular} \\
\hline
\end{tabular}

Exocrine pancreatic function was reported by Cahen 2007. In the endoscopic group, exocrine pancreatic insufficiency developed in six out of six patients (100\%) with intact exocrine pancreatic function at baseline, compared to one out of four patients (25\%) in the surgical group. The difference was statistically significant (Table 1).

\section{Number of needed endoscopic and surgical procedures}

Both studies reported on this outcome but the data were not suitable for pooling. Cahen 2007 showed that patients in the surgical group underwent significantly fewer procedures than patients in the endoscopic group (Table 1). Dite 2003 only reported this outcome for the complete cohort (both randomised and non-randomised patients). Patients in the surgical group required fewer procedures compared to the endoscopic group (mean of six procedures in the endoscopic group versus one procedure in the surgical group).

\section{Change in nutritional status}

Dite 2003 reported a higher proportion of patients with increases in body weight at the end of the follow-up period in the surgical group compared to the endoscopic group (10 out of 36 (28\%) for the endoscopic group versus 17 out of 36 (47\%) for the surgical group) (Table 1). Although the study claimed that this difference was statistically significant, we could not reproduce the reported $P$ value.

\section{Duration of hospital stay}

Cahen 2007 reported on this outcome (Table 1). There was no evidence for a difference between the two groups.

\section{Surgical intervention versus conservative treatment}

We identified one trial (Nealon 1993) comparing surgical intervention to conservative treatment for CP. We summarised the findings of this study in Table 2. In summary, this study showed a highly significant difference in favour of early surgical intervention compared to conservative treatment in regard to pain relief and pancreatic function. Partial or complete pain relief was observed in 16 out of 17 (94\%) patients in the surgical group versus 2 out of $15(13 \%)$ in the conservative group. The proportion of patients developing new onset endocrine and exocrine pancreatic 
insufficiency was, respectively, 2 out of $13(15 \%)$ and 1 out of 15 (7\%) patients in the surgical group versus 10 out of $12(83 \%)$ and 11 out of $14(79 \%)$ patients in the conservative group.

Results of all outcomes considered to be of critical importance according to the GRADE guideline (that is pain relief, major complications and mortality, quality of life and endocrine and exocrine pancreatic insufficiency) were summarised in the Summary of findings 2 . 


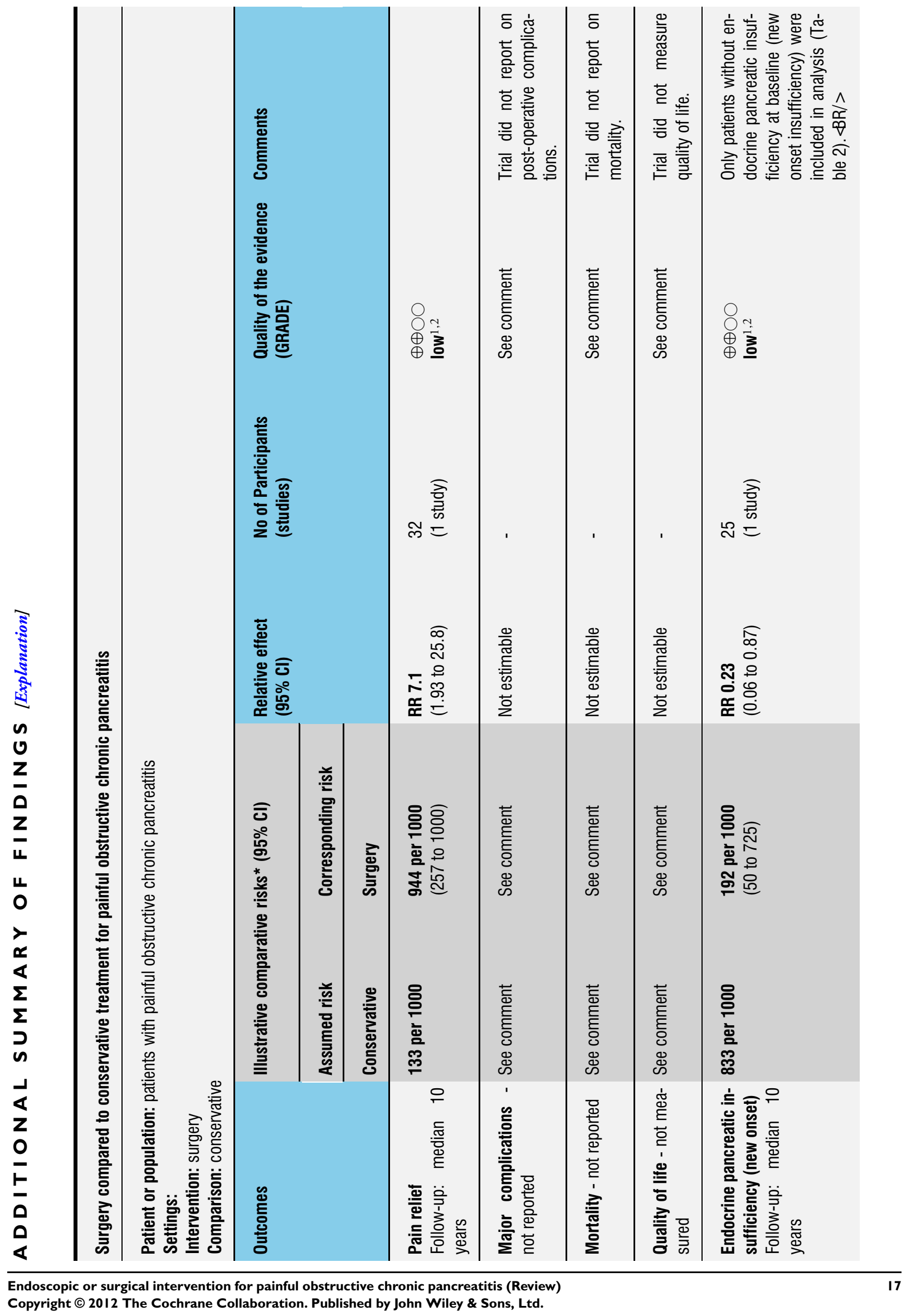




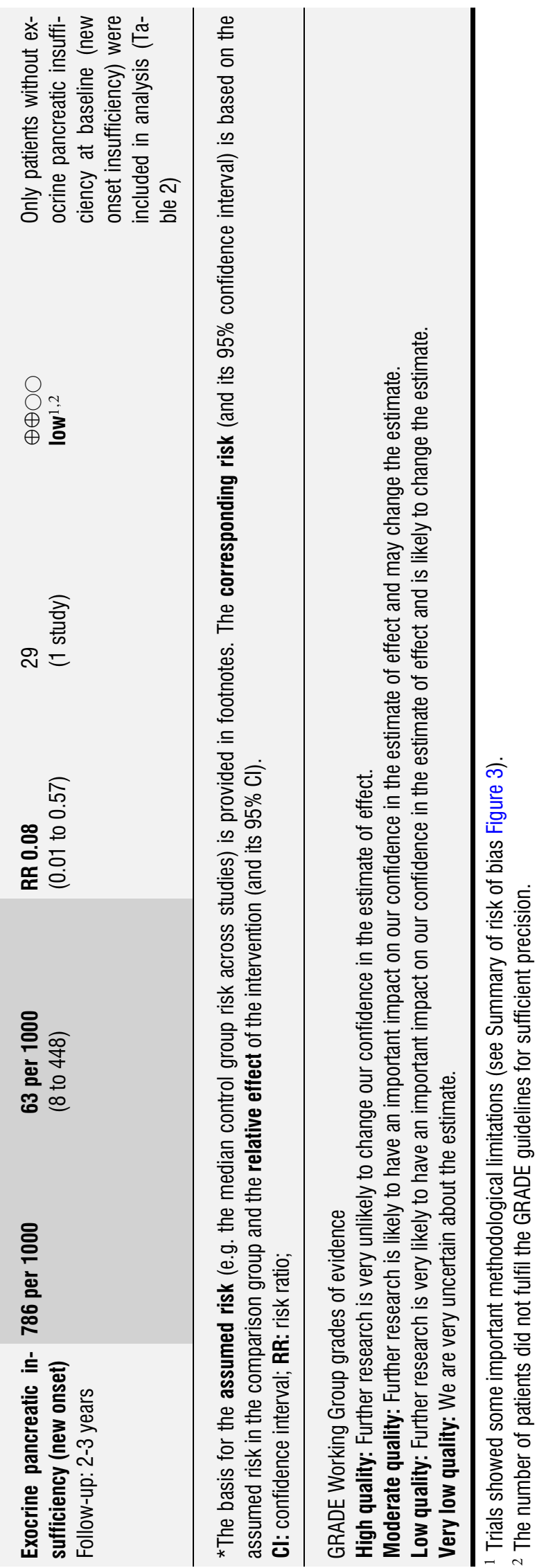

Endoscopic or surgical intervention for painful obstructive chronic pancreatitis (Review)

Copyright $\odot 2012$ The Cochrane Collaboration. Published by John Wiley \& Sons, Ltd. 


\section{DISCUSSION}

\section{Summary of main results}

\section{Endoscopic versus surgical intervention}

The main finding of this review is that surgery achieves pain relief in a higher proportion of patients compared to endoscopic treatment, for patients with obstructive CP. This finding was consistent in the two RCTs included (Cahen 2007; Dite 2003). The observed difference had an evident clinical importance and was long lasting. Additional benefits of surgery compared to endoscopy were reported as well, mainly improved quality of life and a lower risk of developing exocrine pancreatic insufficiency. The available evidence could not identify differences between endoscopy and surgery in terms of morbidity or mortality, mainly due to the small size of the trials.

\section{Surgical intervention to conservative treatment}

This review identified one trial (Nealon 1993) comparing surgical intervention to conservative treatment. This trial observed important differences in terms of pain relief and preservation of pancreatic function in favour of the surgical group. Several methodological and clinical factors, however, impede drawing reliable conclusions from this trial (see the next sections: Overall completeness and applicability of evidence and Quality of the evidence). The main finding of this review regarding this topic is, therefore, that in an early stage of CP surgery rather than conservative treatment seems to be associated with potential benefits, which merits further investigation.

\section{Overall completeness and applicability of evidence}

\section{Endoscopic versus surgical intervention}

Cahen 2007 offered a complete comparison of both treatment modalities with reporting of most outcomes that were of interest to this review. The study of Dite 2003, on the other hand, reported only a limited set of outcomes.

Regarding the applicability of the results, it should be noted that both trials included only patients with severe (late) stage CP (opioid dependency in Cahen 2007 and a period of > five years from diagnosis and three years of failed medical management in Dite 2003). Therefore, results of these trials can only be generalized in patients with similar severity.

Two concerns could be raised regarding the applicability of the results of Dite 2003. First, the study did not exclude patients with an inflammatory mass in the pancreas. The problem is that endoscopy cannot fairly compete with surgery if such masses are present since surgical resection (with or without pancreatic duct drainage) is the treatment of choice in this case (van der Gaag 2007); especially since it was observed that $80 \%$ of the patients in the surgical arm had some type of surgical resection procedure. Secondly, the endoscopic intervention did not include the use of ESWL. This modality is considered by experts to be an important component of optimal endoscopic management (Dumonceau 2007).

The impact of these concerns on the applicability of the study is difficult to assess. It seems acceptable that this could have led to an unbalanced comparison, possibly leading to unjustly favouring surgery over endoscopy. Regarding the first concern, however, the authors did explicitly specify that patients were only included if a consensus between the surgeon and the gastroenterologist was established that both endoscopy and surgery were feasible therapeutic alternatives. Therefore, the population of this trial may more accurately resemble the population expected in the real clinical situation. The authors would thereby have avoided a too narrow patient selection that could compromise external validity (Yusuf 1990). Regarding the lack of ESWL in the endoscopic group, it could be argued that in many centers ESWL is simply not (yet) used as a routine treatment modality for this group of patients. Dite 2003 may, therefore, more accurately resemble the current situation in many hospitals.

\section{Surgical intervention versus conservative treatment}

Nealon 1993 only reported on two outcomes (pain relief and pancreatic function), and the authors especially did not report on potential harms associated with either treatment. This trial thereby only answered one part of the objective of the review. An important point regarding the applicability of the results is that the conservative treatment was not explicitly specified in the report. Also, the exclusion criteria are not clearly listed in the report. This limits the ability to draw conclusions regarding the generalizability of the results.

\section{Quality of the evidence}

\section{Endoscopic versus surgical intervention}

This review included two RCTs with a total of 111 patients. Cahen 2007, despite its small sample size, is a high quality trial with low risk of bias. The results, especially regarding the benefits of surgery in terms of pain relief and quality of life, are convincing both statistically and clinically. The only remark that could be made about the trial is that it was terminated at an unplanned interim analysis. at $80 \%$ of the planned inclusion, due to significant results of benefit. Termination of trials before full inclusion due to benefit carries the risk of overestimating the treatment effect (Montori 2005; Pocock 1999). However, both the observed effect 
as well as the P value have been corrected for this early termination. Moreover, the observed $\mathrm{P}$ value $(\mathrm{P}<0.001)$ and the application of an independent safety commission to take the decision of trial termination give more confidence in the correctness of the decision.

Dite 2003 had several methodological flaws. First, allocation was performed by alternation rather than true randomisation. This method has two problems, the generated allocation is not random and it makes allocation concealment impossible (Randelli 2008). Absence of allocation concealment has been shown to significantly overestimate the treatment effects in RCTs, to up to $40 \%$ (Schulz 1995). In its defence, Dite 2003 did specify that patients were only included if a consensus was established by a consulting gastroenterologist and surgeon regarding the inclusion of patients. While this is by no means a substitution of proper randomisation and allocation concealment, reaching consensus by physicians of two different specialities with competing interests may have reduced the selection bias associated with unconcealed allocation. Further limitations of the study were the exclusion of patients who were non-compliant to follow-up (per protocol analysis rather than an intention-to-treat analysis) and the lack of baseline characteristics. In general, the overall quality and quantity of the available evidence is, in our opinion, sufficient to draw conclusions about benefits of both interventions, especially regarding pain relief. The fact that the two RCTs show consistent results and that the observed differences are more evident (both statistically and clinically) in the study with low risk of bias, increase the reliability of the observed differences. On the other hand, the small size of the trials makes drawing conclusions regarding outcomes with potentially a small difference between the interventions (for example complications and mortality) beyond reach. Also, the lack of evidence of benefit regarding other more objective outcomes (for example pancreatic function) is a drawback in the quality of the evidence.

\section{Surgical intervention versus conservative treatment}

As stated earlier, one trial Nealon 1993 including 32 patients was identified for this comparison. This trial has limitations as the trial had a small sample size and lacked a formal sample size calculation, the conservative arm was not clearly defined, the inclusion of patients was conducted over a long period of time and the methodology was not clearly reported. This could be partly explained by the study being a pilot RCT intended to generate a hypothesis to be tested in a larger randomised trial (Nealon 1993). Another potential explanation is that the study was set up about 18 years ago, in a period when knowledge of the methodology of RCTs was not commonly available.

Taking the above mentioned in mind, this trial is best considered as a hypothesis-generating pilot trial that should lead to further studying of the promising results shown by this trial before conclusions can be drawn for current practice.

\section{Potential biases in the review process}

Obtaining all relevant data was the most challenging aspect of this review. For all studies included, some potentially relevant data were missing in the original reports. We were able to obtain some of these data by contacting the authors of the trials, but despite repeated contacting of authors some data remained missing. Nonetheless, it is not likely that these data would have changed the conclusions of the review, especially since most concerned secondary outcomes.

Finally, this review once again shows that reporting of several aspects in trials, including essential aspects like baseline characteristics, is still inadequate in many cases. This clearly illustrates the need to adhere to guidelines for reporting research to make the validity of studies more assessable. Caution should be applied, however, in critically appraising poorly reported trials since evidence showed that this is not always interchangeable with bad methodology (Soares 2004).

\section{Agreements and disagreements with other studies or reviews}

\section{Endoscopic versus surgical intervention}

A review by Deviere 2008 comparing endoscopic to surgical treatment for CP and including the same two RCTs as in our review concluded that the low number of patients in the trials and the differences in methodology did not allow for drawing any conclusions about the choice between endoscopy and surgery. Deviere 2008 stated that "because of paucity in the available RCTs, physicians and surgeons must rely on their own experience".

We do not entirely agree with these conclusions. Choosing individual experiences and preferences (level $\mathrm{V}$ evidence) as a basis for decision making, despite the availability of two RCTs (level 1 evidence) showing consistent results in favour of one treatment, is in our opinion too conservative. This is especially so since one of these studies is a well conducted study with low risk of bias and the endoscopic treatment in this trial was performed in centres with high expertise and performing of ESWL for large pancreatic duct stones (Cahen 2007). We think that serious efforts should be made to interpret the available evidence in a way that is most beneficial to patients, taking into account the limitations regarding the generalizability and validity of this evidence.

\section{Surgical intervention versus conservative treatment}

Although Nealon 1993 is the only RCT that has compared surgical intervention at an early stage of CP to conservative intervention, the results are in agreement with other non-randomised studies. Clinically, two non-randomised cohort studies have shown that surgical interventions, especially drainage procedures, have the potential to delay the progressive loss of pancreatic function in 
CP patients (Maartense 2004; Nealon 1993). This is in line with findings from experimental studies. In an experimental model of early versus late surgical drainage for $\mathrm{CP}$ in piglets, it was observed that the histology of the pancreas and exocrine pancreatic function were significantly better in the early surgical group compared to the late surgical group (Lamme 2007).

\section{AUTHORS' CONCLUSIONS}

\section{Implications for practice}

\section{Endoscopic versus surgical intervention}

For patients with severe CP (that is with pain intractable to opioid medication) and a dilated pancreatic duct this review shows that surgery is superior to endoscopy in term of benefits (that is pain control and quality of life). However, when it comes to morbidity and mortality, this review is not able to draw reliable conclusions. Therefore, we believe that surgery should be considered the treatment of choice for patients with severe CP, but decisions for either intervention should be made after informing patients about risks associated with both treatments and openly discussing the gaps in current knowledge.

\section{Surgical intervention versus conservative treatment}

Regarding this comparison, this review can not draw reliable conclusions for clinical practice. Surgery rather than conservative treatment at an early stage of CP seems a promising approach, but more evidence is needed.

\section{Implications for research}

\section{Endoscopic versus surgical intervention}

This review identified two aspects regarding the comparison of endoscopic versus surgical intervention for $\mathrm{CP}$ which need further investigation. First, endoscopic and surgical interventions should be compared in regard to morbidity and mortality, preferably in a large well conducted trial. Secondly, the effectiveness and complications of endoscopic versus surgical intervention for patients with early stage CP (rather than late stage CP) should be investigated. Combining these two aspects by conducting a large RCT in patients with early stage CP could be an efficient way to answer both questions simultaneously. Future trials should focus on objective outcomes as well as those that are reported by patients to provide a more complete picture of benefits and harms.

\section{Surgical intervention versus conservative treatment}

This review identified one pilot trial showing that surgery rather than conservative treatment for early CP may bring important benefits to patients in terms of pain relief and preservation of pancreatic function. Investigating these results in a large well conducted RCT, with attention to benefit, harm and cost-effectiveness of both interventions, is recommended.

\section{ACKNOW LEDGEMENTS}

We would like to thank Dr Djuna Cahen for sharing her data with us. We also are grateful to Dr Willieam Nealon for sharing his work for the purpose of this review. Finally, we would like to thank Racquel Simpson, Trials Search Co-ordinator of the Cochrane Upper Gastrointestinal and Pancreatic Diseases Group, for her help and assistance in the development of the search strategies for this review.

\section{R E F E R E N C E S}

\section{References to studies included in this review}

Cahen 2007 \{published data only\}

Cahen DL, Gouma DJ, Nio Y, Rauws EA, Boermeester $\mathrm{MA}$, Busch OR, et al.[Surgical drainage of the pancreatic duct in patients with chronic pancreatitis is more effective than endoscopic drainage: randomized trial]. Nederlandse Tijdschrift voor Geneeskunde 2007;151(47):2624-30.

* Cahen DL, Gouma DJ, Nio Y, Rauws EA, Boermeester MA, Busch OR, et al.Endoscopic versus surgical drainage of the pancreatic duct in chronic pancreatitis. The New England Journal of Medicine 2007;356(7):676-84. [PUBMED: 17301298]

Cahen DL, Gouma DJ, Nio Y, Rauws EA, Boermeester MA, Busch OR, et al.Endoscopic versus surgical drainage of the pancreatic duct in chronic pancreatitis: A prospective randomized trial. Gastrointestinal Endoscopy 2005;61:AB99.

Dite 2003 \{published data only\}

* Díte P, Ruzicka M, Zboril V, Novotný I. A prospective, randomized trial comparing endoscopic and surgical therapy for chronic pancreatitis. Endoscopy 2003;35(7):553-8. [PUBMED: 12822088]

Nealon 1993 \{published data only\}

* Nealon WH, Thompson JC. Progressive loss of pancreatic function in chronic pancreatitis is delayed by main pancreatic duct decompression. A longitudinal prospective analysis of the modified puestow procedure. Annals of Surgery 1993;217(5):458-66. [PUBMED: 8489308] 


\section{References to studies excluded from this review}

Alexakis 2005 \{published data only\}

Alexakis N, Neoptolemos JP. Chronic pancreatitis: Endoscopic versus surgical procedures for pain relief. Pancreatitis: Advances in Pathobiology, Diagnosis and Treatment. Springer, 2005:190-205.

Cahen 2011 \{published data only\} Cahen DL, Gouma DJ, Laramee P, Nio CY, Rauws E, Boermeester MA, et al.Endoscopic versus surgical drainage of the pancreatic duct in chronic pancreatitis: Long-term outcome. Digestive Disease Week. Chicago, 2011.

Chang 2010 \{published data only\}

Chang KJ, Erickson RA, Chak A, Lightdale C, Chen YK, Binmoeller KF, et al.EUS compared with endoscopy plus transabdominal US in the initial diagnostic evaluation of patients with upper abdominal pain. Gastrointestinal Endoscopy 2010;72:967-74.

Connors 1993 \{published data only\} Connors PJ, Friedman LS. Pancreas divisum: to stent or not to stent. Gastroenterology 1993;104:1226-8.

Dumonceau 2007 \{published data only\}

Dumonceau JM, Costamagna G, Tringali A, Vahedi K, Delhaye M, Hittelet A, et al.Treatment for painful calcified chronic pancreatitis: extracorporeal shock wave lithotripsy versus endoscopic treatment: a randomised controlled trial. Gut 2007;56(4):545-52.

Dumonceau JM, Vahedi K, Delhaye M, Morales A, Vandermeeren A, Le Moine O, et al.Extracorporeal shockwave lithotripsy (ESWL) alone compared to ESWL plus endoscopic pancreatic drainage in chronic pancreatitis associated with ductal stones. Gastrointestinal Endoscopy 2003;57:AB87.

\section{Iqbal 2009 \{published data only\}}

Iqbal CW, Moir CR, Ishitani MB. Management of chronic pancreatitis in the pediatric patient: endoscopic retrograde cholangiopancreatography vs operative therapy. Journal of Pediatric Surgery 2009;44:139-43.

Knoefel 1997 \{published data only\}

Knoefel WT, Bloechle C, Izbicki JR. Decompression of the main pancreatic duct can delay progressive loss of pancreatic function in chronic pancreatitis. Zeitschrift fur Gastroenterologie 1997;35:301-3.

\section{Laramee 2010 \{published data only\}} Laramee P, Wonderling D, Cahen DL, Bruno MJ, Dijkgraa MG, Gouma DJ, et al.Surgical versus endoscopic drainage in obstructive chronic pancreatitis: A cost-effectiveness analysis. Digestive Disease Week. New Orleans, 2010.

Lee 2005 \{published data only\} Lee SS, Kim MH, Lee SK, Seo DW, Han JM, Bang SJ. The outcome and prognostic factors of endoscopic pancreatic stent insertion in chronic pancreatitis with pancreatic duct stricture. Gastrointestinal Endoscopy 2005;61:AB194.

Levy 1989 \{published data only\}

Levy P, Bernades P, Belghiti J, Fekete F. Does elective pancreatic surgery modify the long-term mortality of patients with chronic pancreatitis? comparison of operated and non-operated patients. Gastroenterologie Clinique et Biologique 1989;13:A5.

Lipsky 1993 \{published data only\}

Lipsky H. Balloon dilation versus Eder-Puestow: bigger and better?. American Journal of Gastroenterology 1993;88: 609-10.

\section{Noda 2004 \{published data only\}}

Noda A. Availability of oral litholysis therapy and its combination with ESWL and endoscopic treatment in chronic pancreatitis. Gastroenterology 2004;126:A230-1.

Sauer 2008 \{published data only\}

Sauer B, Talreja JP, Ellen K, Ku J, Shami VM, Kahaleh M. Temporary placement, of covered self-expandable metal stent (CSEMS) in the pancreatic duct for management of painful chronic pancreatitis: Preliminary data. Gastrointestinal Endoscopy 2008;67:AB327.

Seiler 2009 \{published data only\} Seiler CM. Prospective randomized single-blinded trial of endoscopic stenting for chronic pancreatitis. Clinical Trials 2009;6:464.

\section{Wagh 2008 \{published data only\}}

Wagh M, McHenry L, Watkins J, Fogel E, Sherman S, Lehman G. Extracorporeal ShockWave lithotripsy (ESWL) with ERCP for management of chronic pancreatitis with pancreatic duct calculi. American Journal of Gastroenterology 2008;103:1267.

\section{References to ongoing studies}

\section{Wilcox 2009 \{published data only\}}

Wilcox CM, Lopes TL. A randomized trial comparing endoscopic stenting to a sham procedure for chronic pancreatitis. Clinical Trials 2009;6:455-63.

\section{Additional references}

\section{AGA 1998}

American Gastroenterological Association. American Gastroenterological Association Medical Position Statement: Treatment of pain in chronic pancreatitis. Gastroenterology 1998;115(3):763-4.

\section{Ammann 1999}

Amman RW, Meullhaupt B. The natural history of pain in alcoholic chronic pancreatitis. Gastroenterology 1999;116 (5):1132-40.

Brazier 1992 Brazier JE, Harper R, Jones NM, O'Cathain A, Thomas KJ, Usherwood T, Westlake L. Validating the SF-36 health survey questionnaire: new outcome measure for primary care. BMJ 1992;305:160-4.

\section{Deviere 2008}

Deviere J, Bell RH Jr, Beger HG, Traverso LW. Treatment of chronic pancreatitis with endotherapy or surgery: critical review of randomized control trials. Journal of Gastrointestinal Surgery 2008;12:640-4. 
Dite 2001

Dite P, Stary K, Novotny I, Precechtelova M, Dolina

$\mathrm{J}$, Lata J, et al.Incidence of chronic pancreatitis in the Czech Republic. European Journal of Gastroenterology and Hepatology 2001;13:749-50.

Fasanella 2007

Fasanella KE, Davis B, Lyons J, Chen Z, Lee KK, Slivka A, et al.Pain in chronic pancreatitis and pancreatic cancer. Gastroenterology Clinics of North America 2007;36:335-64.

Gourgiotis 2007

Gourgiotis S, Germanos S, Ridolfini MP. Surgical management of chronic pancreatitis. Hepatobiliary and Pancreatic Diseases International 2007;6(2):121-33.

\section{Higgins 2002}

Higgins JPT, Thompson SG. Quantifying heterogeneity in a meta-analysis. Statistics in Medicine 2002;21:1539-58.

Higgins 2008

Higgins JPT, Green S, editors. Cochrane Handbook for Systematic Reviews of Interventions 5.0.0 [updated February 2008]. The Cochrane Collaboration, 2008.

\section{Izbicki 1998}

Izbicki JR, Bloechle C, Broering DC, Knoefel WT, Kuechler T, Broelsch CE. Extended drainage versus resection in surgery for chronic pancreatitis: a prospective randomized trial comparing the longitudinal pancreaticojejunostomy combined with local pancreatic head excision with the pylorus-preserving pancreatoduodenectomy. Annals of Surgery 1998;228(6):771-9.

\section{Kjaergard 2001}

Kjaergard LL, Villumsen J, Gluud C. Reported methodological quality and discrepancies between large and small randomised trials in meta-analyses. Annals of Internal Medicine 2001;135(11):982-9.

\section{Lamme 2007}

Lamme B, Boermeester MA, Straatsburg IH, van Buijtenen JM, Boerma D, Offerhaus GJ, et al.Early versus late surgical drainage for obstructive pancreatitis in an experimental model. The British Journal of Surgery 2007;94(7):849-54.

\section{Lankisch 2001}

Lankisch PG. Natural course of chronic pancreatitis.

Pancreatology 2001;1:3-14.

\section{Levy 2006}

Levy P, Barthet M, Mollard BR, Amouretti M, MarionAudibert AM, Dyard F. Estimation of the prevalence and incidence of chronic pancreatitis and its complications. Gastroenterologie Clinique et Biologique 2006;30:838-44.

\section{Maartense 2004}

Maartense S, Ledeboer M, Bemelman WA, Ringers J, Frolich $M$, Masclee AA. Effect of surgery for chronic pancreatitis on pancreatic function: pancreatico-jejunostomy and duodenum-preserving resection of the head of the pancreas. Surgery 2004;135(2):125-30.

\section{Moher 1998}

Moher D, Pham B, Jones A, Cook DJ, Jadad AR, Moher $\mathrm{M}$, et al.Does quality of reports of randomised trials affect estimates of intervention efficacy reported in meta-analyses? . Lancet 1998;352(9128):609-13.

Montori 2005

Montori VM, Devereaux PJ, Adhikari NK, Burns KE, Eggert $\mathrm{CH}$, Briel $\mathrm{M}$, et al.Randomized trials stopped early for benefit: a systematic review. JAMA 2005;294(17): 2203-9.

\section{Pezzilli 2005}

Pezzilli R, Morselli Labate AM, Ceciliato R, Frulloni L, Cavestro GM, Comparato G, et al.Quality of life in patients with chronic pancreatitis. Digestive and Liver Disease 2005; 37:181-9.

Pocock 1999

Pocock S, White I. Trials stopped early: too good to be true? . Lancet 1999;353:943-4.

\section{Randelli 2008}

Randelli P, Arrigoni P, Lubowitz JH, Cabitza P, Denti M. Randomisation procedures in orthopaedic trials. Arthroscopy 2008;24(7):834-8.

RevMan

The Nordic Cochrane Centre, The Cochrane Collaboration. Review Manager (RevMan). 5.0.16. Copenhagen: The Nordic Cochrane Centre, The Cochrane Collaboration, 2008.

Rösch 2002

Rösch T, Daniel S, Scholz M, Huilbregtse K, Smits M, Schneider T, et al.Endoscopic treatment of chronic pancreatitis a multicenter study of 1000 patients with longterm follow up. Endoscopy 2002;34(10):765-71.

\section{Schulz 1995}

Schulz KF, Chalmers I, Hayer R, Altman D. Empirical evidence of bias. JAMA 1995;273(5):408-12.

Soares 2004

Soares HP, Daniels S, Kumar A, Clarke M, Scott C, Swann S, Djulbegovic B. Bad reporting does not mean bad methods for randomised trials: observational study of randomised controlled trials performed by the Radiation Therapy Oncology Group. BMJ 2004;328:22-4.

\section{Spanier 2008}

Spanier BW, Dijkgraaf MG, Bruno MJ. Epidemiology, aetiology and outcome of acute and chronic pancreatitis: an update. Best Practice and Research: Clinical Gastroenterology 2008;22:45-63.

Strate 2005

Strate T, Taherpour Z, Bloechle C, Mann O, Bruhn JP, Schneider C, et al.Long-term follow-up of a randomized trial comparing the Beger and Frey procedures for patients suffering from chronic pancreatitis. Annals of Surgery 2005; 241(4):591-8.

Tringali 2008

Tringali A, Boskoski I, Costamagna G. The role of endoscopy in the therapy of chronic pancreatitis. Best Practice and Research: Clinical Gastroenterology 2008;22(1): $145-65$. 
van der Gaag 2007

van der Gaag NA, Gouma DJ, van Gulik TM, Busch ORC, Boermeester MA. Surgical management of chronic pancreatitis. Alimentary Pharmacology and Therapeutics 2007;26 Suppl 2:221-32.

van Esch 2006

van Esch AA, Wilder-Smith OH, Jansen JB, van Goor H, Drenth JP. Pharmacological management of pain in chronic pancreatitis. Digestive Liver Disease 2006;38(7):518-26.

\section{Wehler 2004}

Wehler M, Nichterlein R, Fischer B, Farnbacher M,

Reulbach U, Hahn EG, et al.Factors associated with health- related quality of life in chronic pancreatitis. American

Journal of Gastroenterology 2004;99:138-46.

Witt 2007

Witt H, Apte Mv, Keim V, Wilson JS. Chronic pancreatitis: challenges and advances in the pathogenesis, genetics, diagnosis, and therapy. Gastroenterology 2007;132(4): 1557-73.

Yusuf 1990

Yusuf S, Held P, Teo KK. Selection of patients for randomised controlled trials: implications of wide or narrow eligibility criteria. Statistics in Medicine 1990;9:73-86.

* Indicates the major publication for the study 


\section{CHARACTERISTICS OF STUDIES}

\section{Characteristics of included studies [ordered by study ID]}

\section{Cahen 2007}

\section{Methods}

Study design: randomised controlled trial

Setting of study: single center, AMC Amsterdam, the Netherlands

Follow-up period: 24 months

Loss to follow-up: one patient in the surgical group

Type of analysis: intention-to-treat analysis

Sample size calculations: yes, a sample size of 50 patients was calculated
Number of participants: 39 (19 in the endoscopy group, 20 in the surgical group) Gender: endoscopy group: 11 males, 8 females; surgery group: 15 males, 5 females Age [mean (SD)]: endoscopy group: 52 years (9); surgery group: 46 years (12) BMI [mean (SD)]: endoscopy group: $21 \mathrm{~kg}$ (4. 1); surgery group: $21 \mathrm{~kg}$ (3. 7) Type of pain:

- endoscopy group: 7 patients with intermittent pain (type A), 12 patients with continuous pain (type B)

- surgery group: 9 patients with intermittent pain (type A), 11 patients with continuous pain (type B)

Inclusion criteria:

- Established CP

- Obstruction of pancreatic duct $(>5 \mathrm{~mm})$

- No pancreatic head enlargement

- Severe recurrent pancreatic pain intractable to non-narcotic analgesics Exclusion criteria:

- Age $<18$ or $>80$ years

- Enlargement of pancreatic head $>4 \mathrm{~cm}$

- Contra-indications to surgery or endoscopic interventions

- Previous pancreatic surgery

- Suspected pancreatic malignancy, or life expectancy $<2$ years

- Pregnancy

Duration of symptoms: endoscopy group: 16 months (SD 14); surgery group 21 months (SD 19)

Ongoing alcohol abuse at randomisation: endoscopy group: 0 patients; surgical group: 5 patients

Ongoing smoking at randomisation: endoscopy group: 15 patients; surgical group: 17 patients
Endoscopic drainage versus surgical drainage:

- Endoscopic drainage: endoscopic drainage of the pancreatic duct by ERCP with (repeated) dilatation and stent placement if required. Patients with large stones in the pancreatic duct $(>7 \mathrm{~mm})$ underwent extracorporeal shock-wave lithotripsy (ESWL) before drainage.

- Surgical drainage: surgical drainage of the pancreatic duct by means of a longitudinal pancreaticojejunostomy as intended treatment. In one patient, a Whipple procedure was performed because of peripancreatic inflammation. In another patient, stone extraction required a Frey procedure. 
Cahen 2007 (Continued)

Endoscopic experience: study interventions were performed by experienced endoscopists (performed > 1000 ERCPs)

Surgical experience: surgical procedures were performed by experienced pancreatic surgeons (no specific criteria stated)

Outcomes

Primary outcome (prespecified in method section):

- Pain score (Izbicki questionnaire)

Secondary outcomes (prespecified in method section):

- Pain relief (defined by Izbicki score)

- Physical and mental health (SF-36 questionnaires)

- Post-interventional complications

- Length of hospital stay

- Number of performed procedures

- Change in pancreatic function

- Mortality

Other outcomes (results reported, but not specified in method section):

- Conversion to surgery

- Technical success of intervention

- Hospital re-admittance

Time points of outcomes: 6 weeks and 3, 6, 12, 18 and 24 months

Notes

- Study was terminated prematurely by the safety committee on the bases of significant difference in outcome favouring the surgical group with a $P$ value of less than 0.001 regarding the primarily outcome (pain on the Izbicki pain score).

- Author provided us with additional methodological information and data.

\section{Risk of bias}

\begin{tabular}{|c|}
\hline Bias \\
\hline
\end{tabular}

Random sequence generation (selection Low risk

Automated assignment system.

bias)

Allocation concealment (selection bias) Low risk Specifically stated.

Blinding (performance bias and detection High risk bias)

All outcomes

Incomplete outcome data (attrition bias) Low risk All outcomes

Selective reporting (reporting bias)

Low risk
Proportion of loss to follow-up did not exceed $20 \%$.

All relevant and pre-specified outcomes reported.

Other bias Low risk

Study terminated prematurely, but authors performed adequate adjustment for treatment effect and $\mathrm{P}$ value for early termination 
Methods
Study design: pseudo-randomised controlled trial (alternating allocation) Setting of study: single center, University Hospital Brno, Czech Republic Follow-up period: 5 years

Loss to follow up: patients not compliant to follow-up were excluded

Type of analysis: per protocol analysis

Sample size calculation: yes, a sample size of 140 patients was calculated

Number of randomised participants: 72 (36 in the endoscopy group, 36 in the surgical group). The population of the RCT is part of a larger prospective cohort reported in the same publication. The total sample of the cohort is 140

Gender: not specified for the randomised group (only for the complete cohort, with 119 males and 21 females)

Age: not specified for the randomised group (only for the complete cohort with a mean age of 41.7 years ranging between 26-53)

BMI: not specified

Type of pain (continuous vs recurrent flair ups): not specified

Inclusion criteria:

- Established CP

- Obstruction of pancreatic duct (dilated pancreatic duct)

- Painful CP (pain score > 3 on the Melzack's pain score)

- Failure of conservative management in the previous 3 years

- Duration clinical CP for more than 5 years

- Consensus of surgeon and gastroenterologist regarding suitability of patient for both endoscopy and surgery

Exclusion criteria:

- Age $<18$ or $>70$ years

- Previous interventional therapy for CP (surgery, endoscopy or nerve block)

- Suspected pancreatic malignancy

- Non-compliance to follow-up examinations

- Pregnancy

Duration of symptoms: $>5$ years (inclusion criteria)

Ongoing alcohol abuse and/or smoking at randomisation: not reported

Interventions
Endoscopic drainage versus surgical intervention (drainage and resection):

- Endoscopic drainage: endoscopic drainage of the pancreatic duct by ERCP with pancreatic sphincterotomy, stone extraction, dilation of strictures and stenting, as appropriate. ESWL was not applied as part of the endoscopic intervention.

- Surgical intervention: choice of operation was dependent on the morphology of the pancreas on pre-operative imaging. Pancreaticojejunostomy was performed in patients with absence of focal pancreatic enlargement. In patients in whom disease was limited predominantly to the pancreatic head, either duodenum-preserving pancreatic head resection or pancreatoduodenectomy (Whipple resection) were performed. CP predominantly affecting the pancreatic tail was treated by left pancreatic resection. Endoscopic experience: study interventions were performed by two experienced endoscopists (performed $>200$ drainage procedures)

Surgical experience: surgical procedures was performed by one abdominal surgeon (performed 90 pancreatic operations before the start of the study) 
Dite 2003 (Continued)

\begin{tabular}{|c|c|}
\hline Outcomes & $\begin{array}{l}\text { Primary outcome (prespecified in method section): } \\
\text { - Pain relief (defined by Melzack score) } \\
\text { - Necessity for further interventions } \\
\text { Secondary outcomes (prespecified in method section): } \\
\text { - Change in body weight } \\
\text { - Presence of diabetes } \\
\text { Other outcomes (results reported, but not specified in method section): } \\
\text { - Complcations } \\
\text { - Mortality } \\
\text { Time points of outcomes: } 6 \text { months and } 1,3 \text { and } 5 \text { years }\end{array}$ \\
\hline Notes & $\begin{array}{l}\text { - The population of the RCT is part of a larger prospective cohort reported in the } \\
\text { same publication. } \\
\text { - Author provided us with additional information regarding methodology of the } \\
\text { study, but not with additional data regarding missing baseline characteristics and } \\
\text { outcomes. }\end{array}$ \\
\hline
\end{tabular}

\section{Risk of bias}

\begin{tabular}{|c|c|c|}
\hline Bias & Authors' judgement & Support for judgement \\
\hline $\begin{array}{l}\text { Random sequence generation (selection } \\
\text { bias) }\end{array}$ & High risk & Allocation by alternation. \\
\hline Allocation concealment (selection bias) & High risk & \\
\hline $\begin{array}{l}\text { Blinding (performance bias and detection } \\
\text { bias) } \\
\text { All outcomes }\end{array}$ & High risk & \\
\hline $\begin{array}{l}\text { Incomplete outcome data (attrition bias) } \\
\text { All outcomes }\end{array}$ & High risk & $\begin{array}{l}\text { Patients not compliant to follow-up were } \\
\text { excluded. }\end{array}$ \\
\hline Selective reporting (reporting bias) & Low risk & All pre-specified outcomes reported. \\
\hline Other bias & Unclear risk & $\begin{array}{l}\text { - The study did not present a baseline } \\
\text { table with relevant patient characteristics } \\
\text { and potential confounders (e.g. smoking, } \\
\text { alcohol use, pre-operative pain, etc). } \\
\text { - Study allowed for inclusion of } \\
\text { patients with enlarged pancreatic head. } \\
\text { These patients potentially benefit more } \\
\text { from surgery than endoscopy, since } \\
\text { surgery allows for resection of the } \\
\text { inflamed mass while endoscopy does not. }\end{array}$ \\
\hline
\end{tabular}


Methods
Study design: randomised controlled trial

Setting of study: single center, The University of Texes Medical Branch, Galveston, Texas Follow-up period: median 124 months

Loss to follow-up: no

Type of analysis: intention-to-treat analysis

Sample size calculations: no (pilot study)

\section{Participants}

Number of participants: 32 patients (17 in the surgical group, 15 in the conservative group)

Gender: not specified

Age [mean]: 41.7 years in the surgical group, 44.6 in the conservative group Inclusion criteria:

\section{- Established CP}

- Dilation of pancreatic duct

- Mild, non-debilitating pain

- Mild to moderate grade of CP: using a self developed grading system (1 point for morphology on ERCP, 2 points for exocrine function, 2 points for endocrine function) . Patients were categorized as mild/moderate ( 3 or less points) or severe CP (more then 3 points).

Exclusion criteria: not specified

Duration of symptoms: not specified

Ongoing alcohol abuse at randomisation: not specified for patients within the RCT

Ongoing smoking at randomisation: not specified
Interventions

\section{Surgical drainage versus conservative treatment}

- Surgical drainage: surgical drainage of the pancreatic duct by means of a longitudinal pancreaticojejunostomy. With choledochoenterostomy and pseudocyst drainage when deemed necessary. In patients with duodenum obstruction a gastrojejunostomy was performed as well.

- Conservative treatment: not specified.

Surgical experience: not specified
Outcomes

\section{Risk of bias}

Primary and secondary outcomes (prespecified in method section): not specified as such Outcomes (specified in method section):

- Presence of abdominal pain

- Grade of CP (using the self developed grading system described above)

Other outcomes (results reported, but not specified in method section):

- Exocrine and endocrine pancreatic function

Time points of outcomes: standardised follow-up each 14 to 16 months
- The population of the RCT is part of a larger prospective cohort reported in the same publication.

- The author only published the results of the first 17 patients. Other data were provided to us by the author for the purpose of this review. 


\section{Nealon 1993 (Continued)}

\begin{tabular}{|c|c|c|}
\hline $\begin{array}{l}\text { Random sequence generation (selection } \\
\text { bias) }\end{array}$ & Unclear risk & $\begin{array}{l}\text { Last digit of the MRI number was used } \\
\text { (odd versus even digits). It is unclear if the } \\
\text { numbers generated by such a mechanism } \\
\text { are truly random }\end{array}$ \\
\hline
\end{tabular}

\begin{tabular}{|c|c|c|}
\hline Allocation concealment (selection bias) & High risk & \\
\hline $\begin{array}{l}\text { Blinding (performance bias and detection } \\
\text { bias) } \\
\text { All outcomes }\end{array}$ & High risk & \\
\hline $\begin{array}{l}\text { Incomplete outcome data (attrition bias) } \\
\text { All outcomes }\end{array}$ & Low risk & $\begin{array}{l}\text { Proportion of losses to follow-up did not } \\
\text { exceed } 20 \% \text {. }\end{array}$ \\
\hline Selective reporting (reporting bias) & Low risk & All specified data were reported. \\
\hline Other bias & Unclear risk & $\begin{array}{l}\text { The study did not present a baseline ta- } \\
\text { ble with relevant patient characteristics and } \\
\text { potential confounders }\end{array}$ \\
\hline
\end{tabular}

\section{Characteristics of excluded studies [ordered by study ID]}

\begin{tabular}{|c|c|}
\hline Study & Reason for exclusion \\
\hline Alexakis 2005 & Abstract was not electronically available. Publication appeared to be a book chapter. Not an original publication \\
\hline Cahen 2011 & $\begin{array}{l}\text { Report is only available in abstract form. This is a long-term report of one of the included trials. Final report } \\
\text { will be added to the review when published }\end{array}$ \\
\hline Chang 2010 & Diagnostic study comparing endoscopic ultrasound with transabdominal ultrasound for upper abdominal pain \\
\hline Connors 1993 & $\begin{array}{l}\text { Abstract was not electronically available. Publication is a comment on another study regarding use of stents in } \\
\text { acute recurrent pancreatitis. Chronic pancreatitis patients were excluded }\end{array}$ \\
\hline Dumonceau 2007 & $\begin{array}{l}\text { Randomised trial comparing endoscopic intervention to an alternative treatment, i.e. extracorporeal shock-wave } \\
\text { lithotripsy (ESWL) }\end{array}$ \\
\hline Iqbal 2009 & Non-randomised trial comparing endoscopic intervention to surgical intervention in pediatric patients \\
\hline Knoefel 1997 & $\begin{array}{l}\text { Abstract was not electronically available. Publication only provides comment on the Nealon } 1993 \text { study. No } \\
\text { original data. }\end{array}$ \\
\hline Laramee 2010 & Publication (only in abstract form) is a report of an economic evaluation based on a review of literature \\
\hline
\end{tabular}


(Continued)

\begin{tabular}{ll}
\hline Lee 2005 & $\begin{array}{l}\text { Abstract was not electronically available. Publication (only in abstract form) is a report of a non-randomised } \\
\text { series }\end{array}$ \\
\hline Levy 1989 & $\begin{array}{l}\text { Abstract was not electronically available. Publication (only in abstract form) is a report of a non-randomised } \\
\text { comparison }\end{array}$ \\
\hline Lipsky 1993 & Abstract was not electronically available. Study compares two techniques for treatment of oesophageal strictures \\
\hline Noda 2004 & $\begin{array}{l}\text { Abstract was not electronically available. Publication (only in abstract form) is a report of a non-randomised } \\
\text { comparison of different methods of litholysis }\end{array}$ \\
\hline Sauer 2008 & $\begin{array}{l}\text { Abstract was not electronically available. Publication (only in abstract form) is a report of a non-randomised } \\
\text { comparison }\end{array}$ \\
\hline Seiler 2009 & $\begin{array}{l}\text { No abstract. Publication is a commentary on a protocol of a randomised trial comparing endoscopic intervention } \\
\text { to sham intervention (Wilcox 2009) }\end{array}$ \\
\hline Wagh 2008 & $\begin{array}{l}\text { Abstract was not electronically available. Publication (only in abstract form) describes a cohort of patients, } \\
\text { without comparison }\end{array}$ \\
\hline
\end{tabular}

\section{Characteristics of ongoing studies [ordered by study ID]}

\section{Wilcox 2009}

\begin{tabular}{|c|c|}
\hline Trial name or title & A randomised trial comparing endoscopic stenting to a sham procedure for chronic pancreatitis \\
\hline Methods & Randomised controlled trial \\
\hline Participants & $\begin{array}{l}\text { Patients with typical abdominal pain, imaging confirmation of } \mathrm{CP} \text { and endoscopic retrograde cholangiopan- } \\
\text { creatography }(\mathrm{ERCP}) \text { confirmation of PD stricture }\end{array}$ \\
\hline Interventions & ERCP with sphincterotomy and PD stenting versus sham procedure \\
\hline Outcomes & $\begin{array}{l}\text { Primary endpoint: reduction in abdominal pain. } \\
\text { Secondary endpoints: reduction in narcotic use as documented by pill counts; improvement in quality of } \\
\text { life as assessed by the quality of life instruments; reduction in healthcare utilization (emergency room, clinic } \\
\text { visits, or hospitalizations); weight gain; return to employment and reduction in number of missed days from } \\
\text { work }\end{array}$ \\
\hline Starting date & Not stated \\
\hline Contact information & $\begin{array}{l}\text { Dr C Mel Wilcox, University of Alabama at Birmingham, Division of Gastroenterology \& Hepatology, } 703 \\
\text { 19th Street South, ZRB Room 633, Birmingham, AL 35294-0007, USA. Tel: (205) 975-4958, Fax: (205) } \\
\text { 934-1546. E-mail: melw@uab.edu }\end{array}$ \\
\hline Notes & \\
\hline
\end{tabular}


DATA ANDANALYSES

Comparison 1. Endoscopy versus surgery

\begin{tabular}{lccll} 
Outcome or subgroup title & $\begin{array}{c}\text { No. of } \\
\text { studies }\end{array}$ & $\begin{array}{c}\text { No. of } \\
\text { participants }\end{array}$ & Statistical method & Effect size \\
\hline 1 Pain relief & 2 & 111 & $\begin{array}{l}\text { Risk Ratio (M-H, Fixed, 95\% CI) } \\
\text { 2isk Ratio (M-H, Fixed, 95\% CI) }\end{array}$ & $\begin{array}{l}\text { Subtotals only } \\
\text { 2 Complete and partial pain relief }\end{array}$ \\
$\quad 2$ & & 111 & Risk Ratio (M-H, Fixed, 95\% CI) & $2.45[1.18,5.09]$ \\
$\quad$ 2.1 Complete pain relief & 2 & 111 & Risk Ratio (M-H, Fixed, 95\% CI) & $1.29[0.83,1.99]$ \\
$\quad$ 2.2 Partial pain relief & 2 & 102 & Risk Ratio (M-H, Fixed, 95\% CI) & $0.98[0.55,1.76]$ \\
3 Endocrine pancreatic & 2 & & & \\
$\quad$ insufficiency (new onset) & & & &
\end{tabular}

\section{Analysis I.I. Comparison I Endoscopy versus surgery, Outcome I Pain relief.}

\begin{tabular}{|c|c|c|c|c|c|}
\hline \multicolumn{6}{|c|}{ Comparison: I Endoscopy versus surgery } \\
\hline \multicolumn{6}{|c|}{ Outcome: I Pain relief } \\
\hline \multirow[t]{2}{*}{ Study or subgroup } & Surgery & Endoscopy & \multirow{2}{*}{$\begin{array}{c}\text { Risk Ratio } \\
\text { M-H,Fixed,95\% Cl }\end{array}$} & \multirow[t]{2}{*}{ Weight } & Risk Ratio \\
\hline & $\mathrm{n} / \mathrm{N}$ & $\mathrm{n} / \mathrm{N}$ & & & M-H,Fixed,95\% Cl \\
\hline Cahen 2007 & $15 / 20$ & $6 / 19$ & $\rightarrow$ & $21.9 \%$ & $2.38[1.17,4.82]$ \\
\hline Dite 2003 & $31 / 36$ & $22 / 36$ & E & $78.1 \%$ & $1.41[1.05,1.89]$ \\
\hline Total $(95 \% \mathrm{CI})$ & 56 & 55 & $\bullet$ & $100.0 \%$ & $1.62[1.22,2.15]$ \\
\hline \multicolumn{6}{|c|}{ Total events: 46 (Surgery), 28 (Endoscopy) } \\
\hline \multicolumn{6}{|c|}{ Heterogeneity: Chi?? = 2.00, df = I $(P=0.16) ; 1 ? ?=50 \%$} \\
\hline \multicolumn{6}{|c|}{ Test for overall effect: $Z=3.34(P=0.00085)$} \\
\hline \multicolumn{6}{|c|}{ Test for subgroup differences: Not applicable } \\
\hline
\end{tabular}




\section{Analysis I.2. Comparison I Endoscopy versus surgery, Outcome 2 Complete and partial pain relief.}

Review: Endoscopic or surgical intervention for painful obstructive chronic pancreatitis

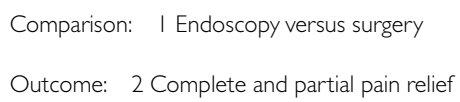

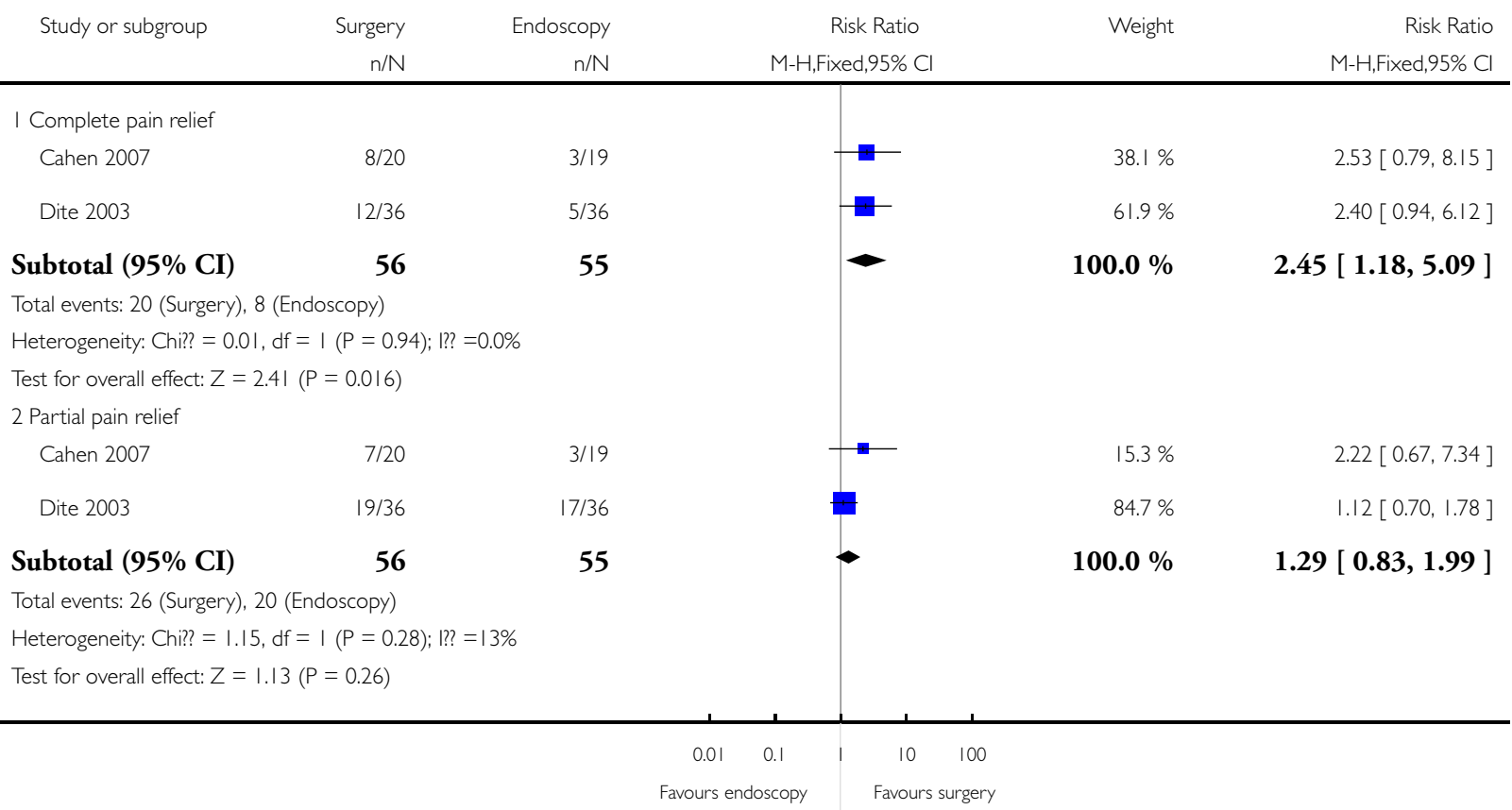




\section{Analysis I.3. Comparison I Endoscopy versus surgery, Outcome 3 Endocrine pancreatic insufficiency (new}

onset).

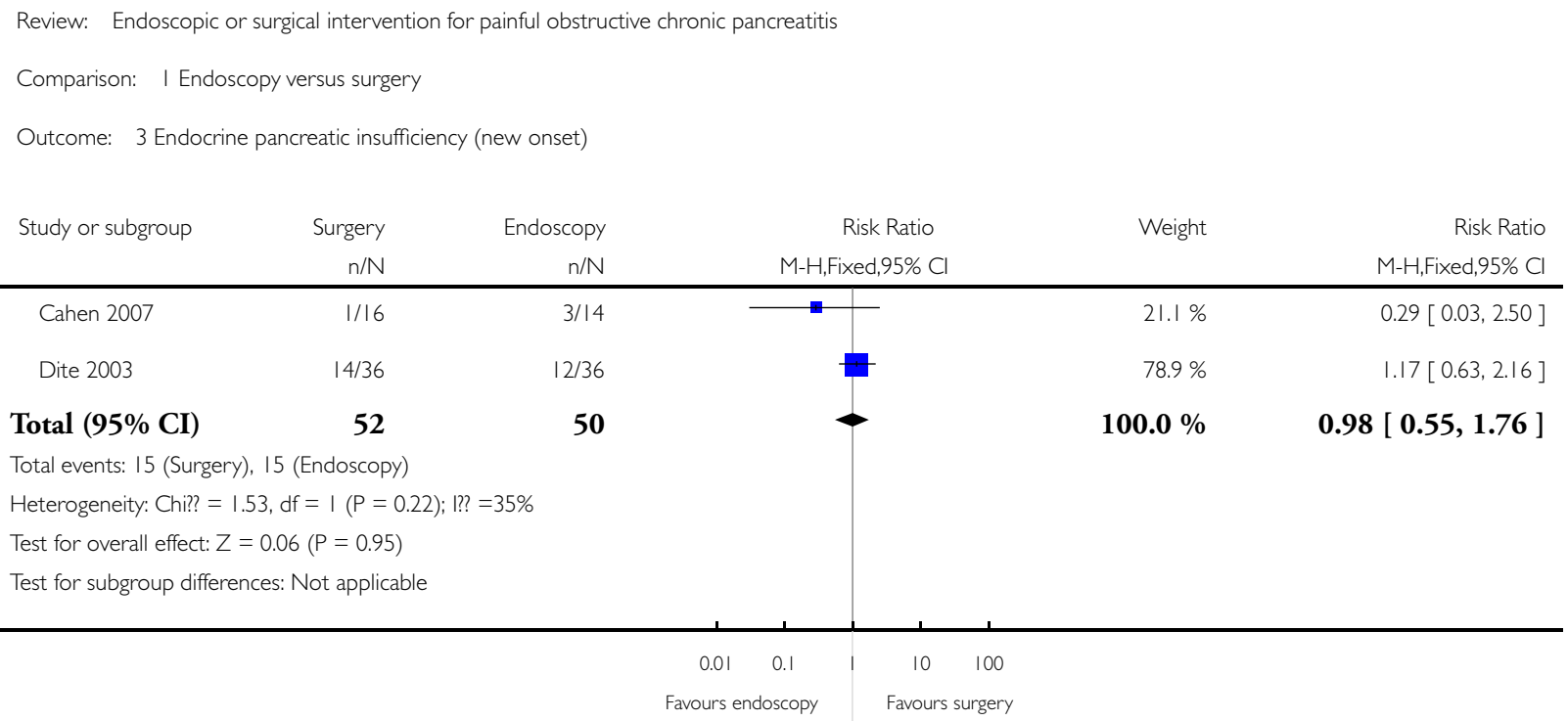

\section{ADDITIONAL TABLES}

Table 1. Results of studies comparing endoscopic to surgical treatment

\begin{tabular}{|c|c|c|c|c|c|c|}
\hline & Cahen 2007 & & & Dite 2003 & & \\
\hline Outcome & $\begin{array}{l}\text { Endoscopy } \\
(\mathrm{N}=19)\end{array}$ & $\begin{array}{l}\text { Surgery } \\
(\mathrm{N}=20)\end{array}$ & P value & $\begin{array}{l}\text { Endoscopy } \\
(\mathrm{N}=36)\end{array}$ & $\begin{array}{l}\text { Surgery } \\
(\mathrm{N}=36)\end{array}$ & P value \\
\hline $\begin{array}{l}\text { Major complica- } \\
\text { tions }[\mathrm{N}(\%)]\end{array}$ & $0(0 \%)$ & $1(5 \%)$ & NS & $5(8 \%)^{*}$ & $3(4 \%)^{*}$ & NS \\
\hline $\begin{array}{l}\text { Mortality } \quad[\mathrm{N} \\
(\%)]\end{array}$ & $1(5 \%)$ & $0(0 \%)$ & NS & $0(0 \%)$ & $0(0 \%)$ & NS \\
\hline \multicolumn{7}{|l|}{$\begin{array}{l}\text { Quality } \\
\text { of life score (SF- } \\
\text { 36) [mean (SD)] }\end{array}$} \\
\hline $\begin{array}{l}\text { - Physical health } \\
\text { component }\end{array}$ & $38(9)$ & $47(7)$ & 0.003 & - & - & - \\
\hline $\begin{array}{l}\text { - Mental health } \\
\text { component }\end{array}$ & $40(9)$ & $45(9)$ & NS & - & - & - \\
\hline
\end{tabular}


Table 1. Results of studies comparing endoscopic to surgical treatment (Continued)

\begin{tabular}{l|l|l|l|l|l}
\hline $\begin{array}{l}\text { Minor complica- } \\
\text { tions }[\mathrm{N}(\%)]\end{array}$ & $6(30 \%)$ & NS & $0(0 \%)^{*}$ & $3(4 \%)^{*}$ \\
\hline $\begin{array}{l}\text { Number of inter- } \\
\text { ventions [mean } \\
\text { (range)] }\end{array}$ & $3(1$ to 21$)$ & $<0.001$ & $6(4 \text { to } 9)^{*}$ & 1 (1 to 3)* & N/A \\
\hline
\end{tabular}

Change in nutri-

tional status $[\mathrm{N}$

$(\%)]$

\begin{tabular}{l|l|l|l|l|l}
\hline $\begin{array}{l}- \text { Increase from } \\
\text { baseline }\end{array}$ & - & - & $10(28 \%)$ & $17(47 \%)$ & NS \\
\hline $\begin{array}{l}\text { Unchanged } \\
\text { from baseline }\end{array}$ & - & - & $9(25 \%)$ & $9(25 \%)$ & NS \\
\hline $\begin{array}{l}\text { Decrese from } \\
\text { baseline }\end{array}$ & - & - & $17(47 \%)$ & $10(28 \%)$ & NS \\
\hline $\begin{array}{l}\text { Duration of hos- } \\
\text { pital stay [me- } \\
\text { dian (range) }\end{array}$ & $11(5$ to 59$)$ & NS 128$)$ & - & & \\
\hline
\end{tabular}

\begin{tabular}{|c|c|c|c|c|c|c|}
\hline & $\begin{array}{l}\text { Endoscopy } \\
(\mathrm{N}=6)^{* *}\end{array}$ & $\begin{array}{l}\text { Surgery } \\
(\mathrm{N}=4)^{* *}\end{array}$ & $P$ value & $\begin{array}{l}\text { Endoscopy } \\
(\mathrm{N}=36)\end{array}$ & $\begin{array}{l}\text { Surgery } \\
(\mathrm{N}=36)\end{array}$ & $\mathrm{P}$ value \\
\hline $\begin{array}{l}\text { Exocrine pancre- } \\
\text { atic insufficiency } \\
\text { (new onset) [N } \\
(\%)]\end{array}$ & $6(100 \%)$ & $1(25 \%)$ & 0.03 & - & - & - \\
\hline
\end{tabular}

* For this outcome Dite 2003 only reported the result for the complete cohort (140 patients, 64 in the endoscopic group and 76 in the surgical group. Only part of the patients were randomised (72 randomised and 68 non-randomised patients).

** $\mathrm{N}$ consists of all patients without exocrine pancreatic insufficiency at baseline.

NS = not significant; N/A = not available.

Table 2. Results of Nealon 1993

\begin{tabular}{|c|c|c|c|}
\hline Outcome & $\begin{array}{l}\text { Surgery } \\
(\mathrm{N}=17)\end{array}$ & $\begin{array}{l}\text { Conservative } \\
(\mathrm{N}=15)\end{array}$ & $P$ value \\
\hline $\begin{array}{l}\text { Pain relief (partial or complete) } \\
{[\mathrm{N}(\%)]}\end{array}$ & $16(94 \%)$ & $2(13 \%)$ & $<0.001$ \\
\hline
\end{tabular}


Table 2. Results of Nealon 1993

\begin{tabular}{lllll}
\hline- Complete pain relief $[\mathrm{N}(\%)]$ & $14(82 \%)$ & $0(0 \%)$ & NS \\
\hline - Partial pain relief $[\mathrm{N}(\%)]$ & $2(12 \%)$ & $2(13 \%)$ & P value \\
\hline & $\begin{array}{l}\text { Surgery } \\
(\mathrm{N}=13)^{*}\end{array}$ & $\begin{array}{l}\text { Conservative } \\
(\mathrm{N}=12)^{*}\end{array}$ & 0.001 \\
\hline $\begin{array}{l}\text { New onset endocrine pancre- } \\
\text { atic insufficiency }[\mathrm{N}(\%)]\end{array}$ & $2(15 \%)$ & $10(83 \%)$ & P value \\
\hline $\begin{array}{l}\text { New onset exocrine pancreatic } \\
\text { insufficiency }[\mathrm{N}(\%)]\end{array}$ & $\begin{array}{l}\text { Surgery } \\
(\mathrm{N}=15)^{*}\end{array}$ & $\begin{array}{l}\text { Conservative } \\
(\mathrm{N}=14)^{*}\end{array}$ & \begin{tabular}{l}
$11(79 \%)$ \\
\hline
\end{tabular}
\end{tabular}

${ }^{*} \mathrm{~N}$ represents the number of patients without exocrine pancreatic insufficiency at baseline.

NS=not significant.

\section{A P P E N DICES}

\section{Appendix I. CENTRAL search strategy}

1. exp Pancreatitis, Chronic/

2. chronic pancreatitis.mp.

3. 1 or 2

4. ((autoimmun\$ or auto-immun $\$$ or Tropical or hereditar $\$$ or familiar\$) and pancreatitis).mp.

5. exp Pancreatitis, Alcoholic/

6. exp Pancreatic Ducts/

7. obstruction.mp.

8. 6 and 7

9. (Pancrea $\$$ adj2 Duct\$ adj2 obstruction\$).mp.

10. 8 or 9

11. alcohol intoxicat\$.mp.

12. (autoimmunity $\$$ or auto-immunity\$).mp.

13. Hypertriglyceridemia/

14. Hypercalcemia/

15. 12 or 11 or 14 or 13

16. Pancreas/

17. 15 and 16

18. 3 or 4 or 5 or 10 or 17

19. Cholangiopancreatography, Endoscopic Retrograde/ or Drainage/ or Endoscopy/ or Endoscopy, Digestive System/

20. ERCP.mp.

21. Decompression/

Endoscopic or surgical intervention for painful obstructive chronic pancreatitis (Review)

Copyright $\Subset 2012$ The Cochrane Collaboration. Published by John Wiley \& Sons, Ltd. 
22. Sphincterotomy, Endoscopic/

23. Dilatation/

24. Stents/

25. or/19-24

26. 16 and 25

27. Surgery/

28. Surgical Procedures, Operative/

29. 27 or 28

30. 29 and 16

31. Pancreaticojejunostomy/

32. beger.mp.

33. Frey.mp.

34. (puestow or Partington-Rochelle).mp.

35. Pancreatectomy/

36. ((left or tail or distal or caudal) and (resection or pancreatectomy)).mp.

37. Pancreaticoduodenectomy/or whipple.mp.

38. (dilation adj2 pancrea $\$$ ).mp.

39. or/31-38

40. 18 or 26 or 30 or 39

\section{Appendix 2. MEDLINE search strategy}

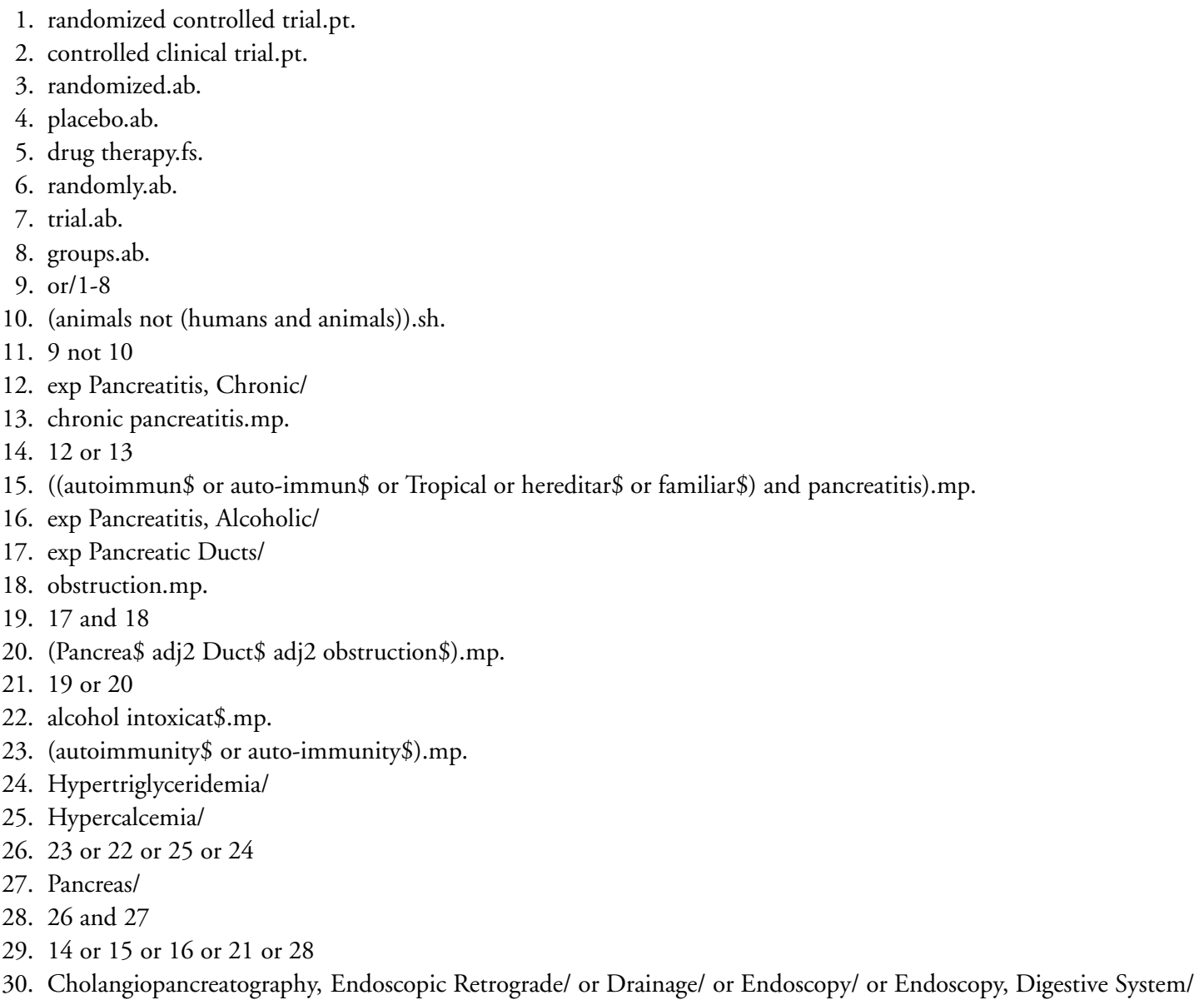

Endoscopic or surgical intervention for painful obstructive chronic pancreatitis (Review)

Copyright $\odot 2012$ The Cochrane Collaboration. Published by John Wiley \& Sons, Ltd. 
31. ERCP.mp.

32. Decompression/

33. Sphincterotomy, Endoscopic/

34. Dilatation/

35. Stents/

36. or/30-35

37. Surgery/

38. Surgical Procedures, Operative/

39. 37 or 38

40. 39 and (14 or 27)

41. Pancreaticojejunostomy/

42. beger.mp.

43. Frey.mp.

44. (puestow or Partington-Rochelle).mp.

45. Pancreatectomy/

46. ((left or tail or distal or caudal) and (resection or pancreatectomy)).mp.

47. Pancreaticoduodenectomy/ or whipple.mp.

48. (dilation adj2 pancrea $\$$ ).mp.

49. or $/ 41-48$

50. 36 or 40 or 49

51. 11 and 29 and 50

\section{Appendix 3. EMBASE search strategy}

1. (random $\$$ or placebo $\$$ ).ti,ab.

2. ((single $\$$ or double $\$$ or triple $\$$ or treble $\$$ ) and (blind $\$$ or mask $\$)$ ).ti,ab.

3. controlled clinical trial\$.ti,ab.

4. RETRACTED ARTICLE/

5. or/1-4

6. (animal\$ not human\$).sh,hw.

7. 5 not 6

8. exp Pancreatitis, Chronicl

9. chronic pancreatitis.mp.

10. 8 or 9

11. ((autoimmun\$ or auto-immun\$ or Tropical or hereditar\$ or familiar\$) and pancreatitis).mp.

12. exp Pancreatitis, Alcoholic/

13. exp Pancreatic Ducts/

14. obstruction.mp.

15. 13 and 14

16. (Pancrea $\$$ adj2 Duct\$ adj2 obstruction\$).mp.

17. 15 or 16

18. alcohol intoxicat\$.mp.

19. (autoimmunit\$ or auto-immunit\$).mp.

20. Hypertriglyceridemia/

21. Hypercalcemia/

22. 19 or 18 or 21 or 20

23. Pancreas/

24. 22 and 23

25. 10 or 11 or 12 or 17 or 24

26. Cholangiopancreatography, Endoscopic Retrograde/ or Drainage/ or Endoscopy/ or Endoscopy, Digestive System/

27. ERCP.mp.

28. Decompression/

Endoscopic or surgical intervention for painful obstructive chronic pancreatitis (Review)

Copyright $\odot 2012$ The Cochrane Collaboration. Published by John Wiley \& Sons, Ltd. 
29. Sphincterotomy, Endoscopic/

30. Dilatation/

31. Stents/

32. or/26-31

33. Surgery/

34. Surgical Procedures, Operative/

35. 33 or 34

36. 35 and (10 or 23 )

37. Pancreaticojejunostomy/

38. beger.mp.

39. Frey.mp.

40. (puestow or Partington-Rochelle).mp.

41. Pancreatectomy/

42. ((left or tail or distal or caudal) and (resection or pancreatectomy)).mp.

43. Pancreaticoduodenectomy/ or Whipple.mp.

44. (dilation adj2 pancrea $\$$ ).mp.

45. or/37-44

46. 32 or 36 or 45

47. 7 and 25 and 46

\section{Appendix 4. Conference Proceeding Index - Science search strategy}

\#1 Topic $=($ chronic pancreatitis $)$ OR Title $=($ chronic AND pancreatitis $)$

\#2 Topic= $(($ autoimmun* OR auto-immun* OR tropical OR hereditar* OR familiar*) AND (pancreatitis) $)$

\#3 Title=((autoimmun* OR auto-immun* OR tropical OR hereditar* OR familiar*) AND (pancreatitis))

\#4 Topic $=\left(\left(\right.\right.$ pancrea* $\left.^{*}\right)$ AND (obstruction OR “alcohol intox*” OR autoimmune* OR auto-immun* OR Hypertriglyceridem* OR Hypercalcem*))

\#5 Title $=(($ pancrea*) AND (obstruction OR “alcohol intox*” OR autoimmune* OR auto-immun* OR Hypertriglyceridem* OR Hypercalcem*))

\#6 \#1 OR \#2 OR \#3 OR \#4 OR \#5

\#7 Topic=((endosc* OR ERCP OR decompression OR drainage OR sphincterotomy OR dilatation OR stent* OR surg* OR beger OR frey OR PJ OR pancreaticojejunostomy OR puestow OR partington-rochelle OR PD OR Pancreaticoduodenectomy OR PPPD OR whipple))

\#8 Title=((endosc* OR ERCP OR decompression OR drainage OR sphincterotomy OR dilatation OR stent* OR surg* OR beger OR frey OR PJ OR pancreaticojejunostomy OR puestow OR partington-rochelle OR PD OR Pancreaticoduodenectomy OR PPPD OR whipple))

\#9 Topic=((left OR tail OR distal OR caudal) AND (resection OR pancreatectomy))

$\# 10$ Title=((left OR tail OR distal OR caudal) AND (resection OR pancreatectomy))

\#11 \#7 OR \#8 OR \#9 OR \#10

\#12 \#6 AND \#11

\section{H I S T O R Y}

Protocol first published: Issue 3, 2009

Review first published: Issue 1, 2012

Endoscopic or surgical intervention for painful obstructive chronic pancreatitis (Review) 


\section{CONTRIBUTIONSOFAUTHORS}

U Ahmed Ali, JM Pahlplatz, HG Gooszen and MA Boermeester participated in the design of this review and drafting of the protocol. U Ahmed Ali, JM Pahlplatz participated in the literature search, extraction of data and methodological quality assessment of studies. U Ahmed Ali, H van Goor, HG Gooszen and MA Boermeester participated in the statistical analysis and interpretation of results. WH Nealon provided data and reviewed the protocol and final manuscript.

U Ahmed Ali and JM Pahlplatz drafted the review.

All authors co-authored the writing of the review, read and approved the final manuscript.

\section{DECLARATIONSOF INTEREST}

None known

\section{SOURCES OF SUPPORT}

\section{Internal sources}

- None, Not specified.

\section{External sources}

- None, Not specified.

\section{DIFFERENCES BETWEEN PROTOCOLANDREVIEW}

This review has been conducted in accordance with the published protocol.

\section{N DEX TERMS}

\section{Medical Subject Headings (MeSH)}

Constriction, Pathologic [complications]; Endoscopy, Gastrointestinal [adverse effects; * methods]; Pain [etiology; *surgery]; Pain Management [ ${ }^{*}$ methods]; Pancreatic Ducts; Pancreatitis, Chronic [ ${ }^{*}$ surgery]; Pressure [adverse effects]; Randomized Controlled Trials as Topic

\section{MeSH check words}

Humans 